NBER WORKING PAPER SERIES

\title{
DISCOVERING ONE'S TALENT: \\ LEARNING FROM ACADEMIC SPECIALIZATION
}

\author{
Ofer Malamud \\ Working Paper 15522 \\ http://www.nber.org/papers/w15522
}

\section{NATIONAL BUREAU OF ECONOMIC RESEARCH \\ 1050 Massachusetts Avenue \\ Cambridge, MA 02138}

November 2009

I wish to thank Nittai Bergman, Kerwin Charles, Claudia Goldin, Caroline Hoxby, Seema Jayachandran, William Johnson, Larry Katz, Bob Lalonde, Derek Neal, Cristian Pop-Eleches, Bruce Sacerdote, two anonymous referees, as well as seminar participants at Clemson University, Hebrew University, Harvard University, Michigan State University, Tel-Aviv University, UCSD, UC Riverside, University of Chicago, and the NBER Higher Education meeting for many helpful suggestions. I am grateful to the Universities Statistical Record, the UK Data Archive, and several university administrators in Scotland and England for assistance. All errors are my own. This work was supported by a grant from the Spencer Foundation. The views expressed herein are those of the author(s) and do not necessarily reflect the views of the National Bureau of Economic Research.

NBER working papers are circulated for discussion and comment purposes. They have not been peerreviewed or been subject to the review by the NBER Board of Directors that accompanies official NBER publications.

(C) 2009 by Ofer Malamud. All rights reserved. Short sections of text, not to exceed two paragraphs, may be quoted without explicit permission provided that full credit, including $\odot$ notice, is given to the source. 
NBER WORKING PAPER SERIES

\title{
DISCOVERING ONE'S TALENT: \\ LEARNING FROM ACADEMIC SPECIALIZATION
}

\author{
Ofer Malamud \\ Working Paper 15522 \\ http://www.nber.org/papers/w15522
}

\section{NATIONAL BUREAU OF ECONOMIC RESEARCH \\ 1050 Massachusetts Avenue \\ Cambridge, MA 02138}

November 2009

I wish to thank Nittai Bergman, Kerwin Charles, Claudia Goldin, Caroline Hoxby, Seema Jayachandran, William Johnson, Larry Katz, Bob Lalonde, Derek Neal, Cristian Pop-Eleches, Bruce Sacerdote, two anonymous referees, as well as seminar participants at Clemson University, Hebrew University, Harvard University, Michigan State University, Tel-Aviv University, UCSD, UC Riverside, University of Chicago, and the NBER Higher Education meeting for many helpful suggestions. I am grateful to the Universities Statistical Record, the UK Data Archive, and several university administrators in Scotland and England for assistance. All errors are my own. This work was supported by a grant from the Spencer Foundation. The views expressed herein are those of the author(s) and do not necessarily reflect the views of the National Bureau of Economic Research.

(C) 2009 by Ofer Malamud. All rights reserved. Short sections of text, not to exceed two paragraphs, may be quoted without explicit permission provided that full credit, including $\odot$ notice, is given to the source. 
Discovering One's Talent: Learning from Academic Specialization

Ofer Malamud

NBER Working Paper No. 15522

November 2009

JEL No. J24

\begin{abstract}
$\underline{\text { ABSTRACT }}$
In addition to providing useful skills, education may also yield valuable information about one's tastes and talents. This paper exploits an exogenous difference in the timing of academic specialization within the British system of higher education to test whether education provides such information. I develop a model in which individuals, by taking courses in different fields of study, accumulate field-specific skills and receive noisy signals of match quality to these fields. Distinguishing between educational regimes with early and late specialization, I derive comparative static predictions about the likelihood of switching to an occupation that is unrelated to one's field of study. If higher education serves mainly to provide specific skills, the model predicts more switching in a regime with late specialization because the cost of switching is lower in terms of foregone skills. Using survey and administrative data on university graduates, I find that individuals from Scotland, where specialization occurs relatively late, are less likely to switch to an unrelated occupation compared to their English counterparts who specialize early. This implies that the benefits to increased match quality are sufficiently large to outweigh the greater loss in skills from specializing early, and thus confirms the important role of higher education in helping students discover their own tastes and talents.
\end{abstract}

Ofer Malamud

Harris School of Public Policy Studies

University of Chicago

1155 East 60th Street

Chicago, IL 60637

and NBER

malamud@uchicago.edu 
"With regard to instruction, economists have made substantial progress in specifying and identifying the economic value of higher education, as it increases the value productivity of human agents as workers... the much neglected activity is that of discovering talent. It, too, can be approached by treating it as a process which provides students with opportunities to discover whether they have the particular capabilities that are required for the type and level of education at which they are working." (Theodore W. Shultz, 1968, p. 331)

\section{Introduction}

Almost 40 years have passed since Theodore Shultz argued that higher education provides students with the opportunity to discover their talents, but relatively little research has explored this important aspect of higher education. In this paper, I use an exogenous difference in the timing of specialization within the British system of higher education to test whether education can provide valuable information about one's talents. In one system, students are required to choose a field of study before they apply to college. In the other, students postpone the decision until late in their college careers. Such differences in the timing of academic specialization highlight the trade-off between accumulating skills in a particular field versus gathering additional information about alternative fields. This paper exploits these differences to examine the importance of higher education in helping students to discover their talents and tastes for different fields of study.

I introduce a simple model of higher education in which individuals can learn about how well they match to different fields by taking courses. I assume that individuals initially take courses in a number of different fields of study but specialize at some point by choosing a particular field in which they must take all of their remaining courses. Each course in a given field of study provides field-specific skills as well as a signal of their match quality to that field. Upon completing their education, individuals choose whether to work in a related field or switch to an occupation that is unrelated to their chosen field of study. ${ }^{1}$ I distinguish between educational regimes with early and late specialization according to the number of courses taken prior to specialization. While later specialization provides students with more time to learn about match quality to different fields, it affords less time to acquire field-specific skills after a field has been chosen. If higher education serves mainly to provide specific skills, the model predicts that students in a regime with late

\footnotetext{
${ }^{1}$ The possibility of switching to an unrelated occupation field is related to the literature on "educational mismatch." However, most of this research focuses on the labor market consequences of being overeducated or undereducated relative to one's job requirements; see Sicherman (1991) and McMillen, Singell, and Seaman (2007).
} 
specialization will be more likely to switch to an occupation that is unrelated to their field of study. This is because the cost of switching in a late regime is lower in terms of foregone skills. On the other hand, if the benefit of higher education comes mainly from providing valuable information about match quality, the incidence of switching to an unrelated occupation will be higher in a regime with early specialization. This is because the benefit associated with higher expected match quality when switching in an early regime will outweigh the greater loss of field-specific skills. By focusing on the decision to switch to an unrelated occupation, these comparative static predictions account for non-pecuniary considerations as well as pecuniary ones.

In order to test whether education provides important information about one's talent, I exploit an exogenous difference in the timing of specialization within the British system of undergraduate education. In England, students apply to a specific field of study at a particular university while still in secondary school. Once admitted to study a certain field, they usually follow a narrow curriculum that focuses on the chosen subject and allows for few courses in other fields. English students are thus required to specialize early. In contrast, Scottish students are typically admitted to a broad faculty rather than a specific field. They are required to study several different fields during their first two years before specializing in a particular field. Scottish students are therefore required to generalize early and specialize late. Comparing England and Scotland is valuable because, while their educational systems are separate and arguably exogenously different, their labor markets are relatively well integrated and macroeconomic policies are determined by a common government. Furthermore, Wales serves as a useful "placebo test" because students there specialize at the same time as in England. Britain is thus a particularly appropriate setting in which to test the comparative static predictions generated by the model.

Using university administrative data and survey data on college graduates, I find that individuals from Scotland, who specialize relatively late, are less likely to switch to an unrelated occupation than their counterparts from England. This difference continues to hold when controlling for field of study and region of work. The pattern is even more striking when I instrument for English and Scottish degrees with region of prior residence. In contrast, I find no difference in the probability of switching between England and Wales where the timing of academic specialization is similar. As further evidence that academic specialization is driving the main results, I find no difference in the probability of switching between England and Scotland at the graduate level where the 
timing of specialization is similar. These findings indicate that the return to match quality is high relative to the return to specific skills. In other words, the fact that England - a regime with early specialization - exhibits a higher incidence of switching implies that the benefits to increased match quality are substantial, and, indeed, large enough to outweigh the greater loss of skills. The data thus confirm that undergraduate education has an important role in helping students discover their tastes and talents.

The notion that individuals may discover their talents and learn about their match quality to different fields is a prominent feature in models of job turnover. ${ }^{2}$ Thus, for example, Jovanovic and Nyarko (1996) explore whether job market experience provides information about a worker's innate traits or raises productivity on specific tasks. But few papers have explicitly considered the role of education. Johnson (1978) postulates that education provides workers with information about their general ability and concludes that education may lower job mobility by reducing its role in acquiring information. ${ }^{3}$ More recently, Hvide (2003) extends Spence's (1973) signaling model to allow for learning about overall ability and suggests that certain types of education, such as U.S. college degrees, may primarily provide information about ability, while others, such as U.K. college degrees, serve to augment productivity. In this paper, the process of accumulating skills and learning about unobserved match quality in different fields of study is made explicit. Altonji (1993) also introduces a model where individuals learn their preference between two fields of study by attending college while Arcidiacono (2004) estimates a structural model of student learning. However, by embedding both skill acquisition and learning within a model of academic specialization, this paper derives and tests a simple comparative static prediction for the importance of learning about one's talents through higher education.

The paper proceeds as follows: Section 2 outlines a simple model of academic specialization and derives comparative static predictions across regimes with early and late academic specialization. Section 3 explores the differences between the English and Scottish systems of higher education in more detail. Section 4 describes the data and the empirical methodology. Section 5 presents results from the regression analysis. Section 6 concludes.

\footnotetext{
${ }^{2}$ McCall (1990), Miller (1984), Neal (1999), and Shaw (1987) extend the notion of job match quality presented by Johnson (1978) and Jovanovic (1979) to the occupational level and present some evidence for learning about occupational match quality.

${ }^{3}$ In a related paper, Johnson (1979) explores the positive relation between general education and occupational mobility and shows that exogenous general education raises the probability of job change.
} 


\section{A Simple Model of Academic Specialization}

This section develops a simple model of academic specialization: Suppose individuals take $n$ courses in each of $k$ fields of study prior to specialization. Each course in a given field provides field-specific skills and a noisy signal of match quality in that field. In specializing, individuals choose a field and take $(N-n k)$ additional courses in this chosen field of study. After completing a total of $N$ courses, individuals choose whether to work in an occupational field that is related to their chosen field of study or to switch to an unrelated occupation. Upon entering the labor market, individuals enjoy returns that are increasing in both match quality and field-specific skills. I describe this basic setup in greater detail below. Then, I proceed to compare the probability of switching between an early regime in which individuals are required to specialize after $n^{E}$ courses in each field and a late regime in which individuals are required to specialize after $n^{L}$ courses in each field, where $n^{E}<n^{L}$. Analytical proofs are relegated to the Mathematical Appendix which offers a more formal treatment of the model.

\subsection{Setup}

Assume that individuals are risk neutral and have identical prior distributions on match quality for each field. Specifically, assume that match quality, $\theta_{i}$, in each field $i$ is a random draw from a normal distribution with the same mean and variance, so that $\theta_{i} \sim N\left(\mu, \sigma_{0}^{2}\right)$. Match quality is therefore uncorrelated across fields and can include any field-specific component of education that affects utility, either directly or through wages - for example, innate ability or interest which contributes to productivity or enjoyment of working in a specific field. In the empirical analysis, I will attempt to control for indicators of predictable match quality so that the remaining components of match quality are random. In fact, we may expect prior distributions to differ across fields. Allowing for different prior means is straightforward and would not alter any of the results from the model. Differences in prior variances would introduce option value considerations similar to ones considered by Johnson (1978) and Miller (1984) so we abstract from them to keep the model parsimonious. I discuss extending the model to allow for different prior variances and risk aversion in section 2.5.

By taking courses in a given field, individuals will (i) accumulate field-specific skills and (ii) receive noisy signals of their match quality to that field. For simplicity, suppose that the quantity 
of skills accumulated in a field, $s_{i}$, is equivalent to the number of courses spent studying that field. Each course of study $j$ in field $i$ provides a signal of match quality in that field, $x_{i j}=\theta_{i}+\varepsilon_{i j}$ where $\varepsilon_{i j} \sim N\left(0, \sigma^{2}\right)$ and $j=1, \ldots, n$. Noise in the signal may be due to any number of idiosyncratic factors such as the quality of instruction or the particular circumstances of the student at the time. I assume that skills are perfectly specific to a particular field but I will consider the possibility of spillovers across fields in section 2.5.

The overall returns to field $i$ upon entering the labor market is an increasing function of both match quality and skills: $u_{i}=u\left(\theta_{i}, s_{i}\right)$ with $\frac{\partial u}{\partial \theta}>0$ and $\frac{\partial u}{\partial s}>0$. For simplicity, I assume that returns are a linear function of match quality and skills, $u\left(\theta_{i}, s_{i}\right)=\alpha \theta_{i}+\beta s_{i}$. I take $\left(\frac{\alpha}{\beta}\right)$ as an indication of the return to match quality relative to the return to specific skills. More generally, we might expect the presence of additional random shocks which cannot be learned about in advance. Furthermore, we expect returns to differ across different fields. In the empirical analysis, I compare outcomes for individuals controlling for field of study so that mean differences across fields can be ignored.

\subsection{Choice of field at specialization}

The posterior distribution of match quality after studying $n$ courses in field $i$ is a normal distribution with mean $\mu_{i}^{\prime}$ and variance $\sigma^{\prime}{ }^{4}$ And the quantity of skills in each field at the point of specialization is $s^{\prime}=n$. Therefore, in specializing, risk neutral individuals with identical prior distributions across fields will choose the field of study with the highest expected returns:

$$
\text { choose } i^{*}=\arg \max _{i=1, \ldots k}\left\{E\left[u\left(\mu_{i}^{\prime}, s^{\prime}\right)\right]\right\}
$$

Since the quantity of specific skills in each field is identical, individuals simply choose the field with the highest posterior mean of match quality, $i^{*}=\arg \max _{i=1, \ldots k}\left\{\mu_{i}^{\prime}\right\}{ }^{5}$ Thus, the posterior mean of match quality in the chosen field at the time of specialization will be $\mu_{i^{*}}^{\prime}{ }^{6}$

\footnotetext{
${ }^{4}$ The posterior mean is a weighted average of the prior mean and the mean of the signals: $\mu_{i}^{\prime}=$ $\left(\mu \sigma_{0}^{-2}+\sigma^{-2} n \bar{x}_{i}\right) /\left(\sigma_{0}^{-2}+n \sigma^{-2}\right)$ where $\bar{x}_{i}=\frac{1}{n} \sum^{j} x_{i j}$. The posterior variance is $\sigma^{\prime}=\left(\sigma_{0}^{-2}+n \sigma^{-2}\right)^{-1}$. See DeGroot (1970) for a detailed exposition.

${ }^{5}$ Strictly speaking, expected future utility should include expected skills rather than the quantity of skills at the point of specialization. But since expected match quality and skills are separable and individuals are risk neutral, this will lead to the same choice at the point of specialization

${ }^{6}$ Specifically, $\mu_{i^{*}}^{\prime}=\left(\mu \sigma_{0}^{-2}+\sigma^{-2} n \max _{i} \bar{x}_{i}\right) /\left(\sigma_{0}^{-2}+n \sigma^{-2}\right)$.
} 


\subsection{Decision on whether to switch}

Following specialization, individuals take $(N-n k)$ additional courses in the chosen field. Hence, the quantity of skills in the chosen field prior to entering the labor market is $s^{\prime \prime}=n+(N-n k)$. Individuals will also receive additional signals in the chosen field, $i^{*}$. Define these signals as $y_{i^{*} l}=$ $\theta_{i^{*}}+\varepsilon_{i^{*} l}$, where $l=n k, \ldots, N$. Consequently, the posterior distribution of match quality in the chosen field after $(N-n k)$ additional signals will be a normal distribution with mean $\mu_{i^{*}}^{\prime \prime}$ and variance $\sigma^{\prime \prime} .^{7}$ Now, given the opportunity to switch to another field prior to entering the labor market, individuals will compare expected returns in the chosen field with expected wages in the next best field:

$$
\text { field switch } \Longleftrightarrow E\left[u\left(\mu_{i^{*}}^{\prime \prime}, s^{\prime \prime}\right)\right]<\max _{i \neq i^{*}} E\left[u\left(\mu_{i}^{\prime}, s^{\prime}\right)\right]
$$

Intuitively, individuals will switch if the posterior mean of match quality in the chosen field falls sufficiently far below the posterior mean of another field to outweigh the loss in specific skills from switching. Note that, if individuals do decide to switch, they will always choose the field with the second-highest posterior mean since all fields other than the one chosen are associated with the same quantity of specific skills and posterior variance. The decision about whether to switch can therefore be framed as a comparison between the first best field, $i^{*}$, and the field that was second best at the time of specialization, $i^{a}$. The field selected after the second stage will be denoted $i^{* *}$ where $i^{* *} \in\left\{i^{*}, i^{a}\right\}$.

\subsection{Probability of field switching}

Now consider the likelihood of switching to an alternative occupational field prior to entering the labor market. Posterior distributions at the time of specialization will be more diffuse for individuals in the early regime. Moreover, these individuals will receive more signals in the chosen field after specializing than their counterparts in the late regime. Thus, in the early regime, assessments of perceived match quality in the chosen field will experience relatively greater updating and make individuals more likely to conclude that they made a mistake when they initially inferred which

\footnotetext{
${ }^{7}$ So that $\mu_{i^{*}}^{\prime \prime}=\left(\mu \sigma_{0}^{-2}+\sigma^{-2} n \max _{i} \bar{x}_{i}+\sigma^{-2}(N-n k) \bar{y}_{i^{*}}\right) /\left(\sigma_{0}^{-2}+n \sigma^{-2}+(N-n k) \sigma^{-2}\right)$ where $\bar{x}_{i}=\frac{1}{n} \sum^{j} x_{i j}$ and $\bar{y}_{i^{*}}=\frac{1}{(N-n k)} \sum^{l} x_{i^{*} l}$ and $\sigma^{\prime \prime}=\left(\sigma_{0}^{-2}+n \sigma^{-2}+(N-n k) \sigma^{-2}\right)^{-1}$.
} 
field had the highest match quality. ${ }^{8}$ However, in switching, individuals will lose the additional skills acquired in the chosen field of study through specialization. Individuals will therefore switch only if the posterior mean of the first-best field falls sufficiently below that of the second best field to outweigh the loss in specific skills. Since the loss in specific skills is always be greater in the early regime, whether switching is higher in the early or late regime will depend on the relative return of match quality.

Proposition 1 A regime with early specialization, $n^{E}$, will have higher rates of switching than a regime with late specialization, $n^{L}$, only if the return to match quality is sufficiently higher than the return to specific skills:

$$
P(\text { switch })^{E}>P(\text { switch })^{L} \Longleftrightarrow \frac{\alpha}{\beta}>C>0
$$

Figure 1 plots the probability of switching for an early and a late regime over the full range of relative returns to match quality which are normalized by taking $\beta=(1-\alpha)$ so that $(\alpha / \beta)$ goes from 0 to $\infty$ as $\alpha$ goes from 0 to $1 .^{9}$. Since the model abstracts from other reasons for switching fields, no switching occurs in either regime if the return to match quality is sufficiently low. However, by introducing an additional stochastic element to the model, i.e. $u\left(\theta_{i}, s_{i}\right)=\alpha \theta_{i}+\beta s_{i}+\epsilon_{i}$ where $\epsilon_{i} \sim N\left(0, \tau^{2}\right)$, switching can take place even if the return to match quality is zero. Allowing for these additional random shocks, we can derive the following corollary:

Corollary 1 If there is no return to information about match quality $(\alpha=0)$ or taking courses does not provide information about match quality $\left(\sigma^{2}=\infty\right)$ then a regime with early specialization, $n^{E}$, will have lower rates of switching than a regime with late specialization, $n^{L}$.

Note the subtle distinction between the return to information on match quality, $\alpha / \beta$, and the quality of information on match quality provided by undergraduate courses, $\sigma^{2}$. But in either case, a regime with early specialization would be expected to have a lower rate of switching than a regime with late specialization. Observing a higher rate of switching in an early regime than in a

\footnotetext{
${ }^{8}$ Specifically, the posterior distribution is more likely to shift in response to the additional information received in the early regime. Hence, the mean of the posterior distribution of the chosen field is also more likely to move below the posterior mean of the second best field at specialization and indicate a perceived mistake. This is particularly intuitive in the case where individuals specialize immediately prior to entering the labor market. In this case, the probability of perceiving a mistake will be zero since no additional information is received following specialization.

${ }^{9}$ All simulations are based on 5000 repetitions for $k=2, N=21, \mu_{1}=\mu_{2}=0, \sigma^{2}=100$, and $\sigma_{0}^{2}=25$. Early regimes are characterized by $n^{E}=2$; late regimes are characterized by $n^{L}=6$. Expected wages are determined according to $E\left(w_{i}\right)=E\left(\alpha \theta_{i}+\beta \widehat{s_{i}}\right)$ where $\widehat{s i}=\frac{s_{i}}{N / k}+\mu$ are normalized skills.
} 
late regime would imply that education provides valuable information on match quality and that this information strongly affects the returns to education.

Focusing on the probability of switching to an unrelated occupation may appear to be an indirect way of testing whether education provides information about match quality. Indeed, according to this model, the trade-off between learning about match quality and accumulating specific skills is central to optimal timing of specialization in higher education. With later specialization, students have more time to learn about match quality in each field but less time to acquire specific skills once a field is chosen. Figure 2 simulates expected wages for an early and a late regime for the full range of relative returns to match quality. Clearly, observing higher overall returns in the late regime would also serve to indicate that the relative return to match quality is high. But it is very difficult to obtain empirical measures that capture all of the returns to occupational choice. Since the decision to switch to an unrelated occupational field encompasses non-pecuniary considerations as well as pecuniary ones, there a significant advantage in focusing on the likelihood of switching. ${ }^{10}$

\subsection{Extensions}

Throughout I have assumed that individuals are risk neutral. Introducing risk aversion does not alter the decision at the point of specialization because the variances of the posterior distributions across fields are identical; individuals would continue to choose the field with the highest posterior mean. However, in considering a field switch, the presence of risk aversion would make the relative variances of the posterior distributions relevant. Specifically, switches would be less common because, even in instances where the chosen field has a lower posterior mean than another field, its lower variance could be sufficiently valuable to risk-averse individuals so as to prevent switching. Moreover, this effect is stronger in the early regime since the trade-off between the posterior variances at the time of specialization and the posterior variance of the chosen field after the receipt of additional signals is more extreme. Field switching would therefore decline more in the early regime than in the late regime due to the presence of risk aversion.

The assumption that prior distributions on match quality are identical across fields implies that individuals do not need to consider the possibility of later switching when making their initial

\footnotetext{
${ }^{10}$ This is especially important in light of Arcidiacono's (2004) finding that most sorting across majors is due to different preferences rather than differential monetary returns to ability.
} 
choice of field at the point of specialization. Allowing for prior variances on match quality to vary by field introduces option value considerations. These would push individuals to specialize in riskier fields because they could switch in case of a bad realization. Moreover, fields with a larger prior variance would have greater option value in the early regime than in the late regime. With more signals following specialization, greater updating in the early regime generates a higher probability that the ultimate posterior mean will surpass that of the chosen field. Hence, individuals in the early regime would be more likely to choose a field with a lower posterior mean at the point of specialization because of the greater option value. Since, on average, such fields have lower expected match quality than those with the highest posterior mean, we expect more field switching in the early regime due to option value considerations. ${ }^{11}$

As it stands, the model contains no truly general skills. A person has general skills only in the sense of having greater levels of specific skills in a variety of alternative fields, and this affects returns only when switching into one of these fields. Nevertheless, it would be relatively simple to incorporate general skills by including some measure of average skill in the fields not chosen for specialization: for example, $\bar{s}=\frac{1}{J} \sum^{j \neq j^{*}} s_{j}$. Introducing such general skills would not alter the main predictions of the model. More generally, we can consider the possibility of spillovers in skills across fields. This would serve to lessen the trade-off between skills and match quality because additional learning about match quality would be less costly in terms of forgone skill acquisition.

\section{Background: Higher Education in Britain}

The British system of higher education provides a particularly appropriate setting in which to examine the predictions of the model. Undergraduate education in England and Scotland, though similar in aim and overall structure, varies widely in the timing of academic specialization. In England, students apply to a specific field of study at a particular university. ${ }^{12}$ Once admitted to a specific field, English students usually follow a narrow curriculum that focuses on the main

\footnotetext{
${ }^{11}$ However, this effect will be small because all fields are sampled prior to specialization and the option value needs to be greater than the difference in the posterior means of match quality between the relevant fields. Furthermore, the presence of risk aversion would counteract the benefits of having high variance in the posterior distributions.

${ }^{12}$ There some exceptions: for example, students in Cambridge are accepted into the engineering faculty and only specialize in a certain sub-field of engineering during the course of their studies.
} 
field and allows for little exposure to other fields. ${ }^{13}$ Indeed, most universities in England require students who switch fields of study to start university anew (though several do allow for some limited switching across related fields). In contrast, Scottish students are typically admitted to a faculty rather than a department; in some universities, admission is to the university at large. Furthermore, they are required to study several different fields during their first two years. As an undergraduate prospectus for the University of Edinburgh explains:

"You would normally take courses in three or more subjects in the first year and, commonly, these are followed by second courses in at least two of the subjects in your second year. This will then give you a choice from two, or even three, subjects to pursue to degree level, and you can delay this decision until quite a late stage...In choosing courses to be taken in the first two years, you can select from a very wide range of courses offered across several faculties."

Similar course structures exist in most Scottish universities. Scottish universities thus allow for substantial choice among fields of study within faculties and, to some degree, across faculties as well. ${ }^{14}$ Students in Scotland are required to take a broader range of courses and choose a field of study much later than their English counterparts. ${ }^{15}$ Given these differences, it is quite natural to regard the English system of higher education as an "early regime" and the Scottish system of higher education as a "late regime".

There is some variation in the average length of the undergraduate degree between England and Scotland. Although there is some heterogeneity among degrees within each nation, most English degrees are completed within 3 years whereas most Scottish degrees are completed within 4 years. However, many Scottish students enter university after 6 years of secondary schooling rather than the 7 years customary in England. According to this calculation, English and Scottish students who attain a BA degree receive roughly the same number of years of schooling (and this is confirmed in the data by examining the age of graduation). Loosely speaking, the first year of university in Scotland may be said to correspond to the final year of secondary school in England. But even

\footnotetext{
${ }^{13}$ Again, there are exceptions: for example, in Cambridge, the system of Tripos allows some flexibility in making changes to courses of study; and certain universities offer courses of study, such as Oxford's PPE (Politics, Philosophy, Economics) course, that allow students to study a broader range of subjects.

${ }^{14}$ Note, however, that changing across certain fields is not always possible (e.g. from history to physics without the necessary prerequisites). Moreover, certain professional faculties, such as medicine and law, are more insular. Engineering is usually a separate faculty but changes from the physical sciences are often permitted.

${ }^{15}$ Numerous scholars of British educational systems have noted that Scottish institutions allow for later specialization than English ones: e.g. Evans (1976), Hunter (1971), Osborne (1967), Squires (1987). Personal conversations and correspondences with university administrators in England and Scotland confirm these observations. This is also supported by evidence that the proportion of individuals that change their field of study between admission and graduation in Scottish universities is more than double that of English universities under various classifications of fields.
} 
so, since English students apply to university in the beginning of their final year of secondary school while Scottish students only make their final choice of field at the end of their second year of university, there is substantial difference in the timing of specialization.

The difference between English and Scottish universities arose from their unique respective historical traditions. English universities were largely independent and free to set their curriculum and course structures. Long into the nineteenth century, Oxford and Cambridge maintained their focus on the traditional subjects (classics, Aristotelian philosophy, and mathematics) with less emphasis on modern subjects such as natural science. (Evans, 1975) The provincial civic universities established later in urban centers did not substantially depart from the traditions of the "ancient" universities. Even with the introduction of broad faculties and additional courses of study, admissions remained at the departmental level. ${ }^{16}$ On the other hand, Scottish universities became regulated under the Universities (Scotland) Act of 1858 that set up an executive commission to draw up uniform conditions for courses of study. The Universities (Scotland) Act of 1889 further increased the choice of subjects available in Scottish universities, reflecting the "traditional Scottish preference for a broad general education." (Hunter, 1971, p. 237) In large part, these two Acts of Scottish Parliament determined the distinctive characteristics of universities in Scotland, including the emphasis on late academic specialization.

In addition to differences in higher education, England and Scotland also differ in their system of secondary school education. In England, students need GCE Advanced-level examinations (Alevels) in 2 or 3 subjects to gain acceptance into university. ${ }^{17}$ In 1989, a new exam, the Advanced Supplementary examination (AS-level) was brought in to broaden the curriculum; it was to be the same standard as an A-level, but half the content. Students were encouraged to substitute two AS-levels for one of their A-levels but most universities did not regard these examinations as commensurate alternatives and it did little to change the character of English secondary school education. In Scotland, on the other hand, students need SCE Higher Examinations in 5 or 6

\footnotetext{
${ }^{16}$ There is one important exception in the University of Keele which gained full independent status in 1962, and implemented an experimental modular curriculum.

${ }^{17}$ Interestingly, the introduction of A-levels in 1951 to replace the Higher School Certificates was a response to the criticism that these latter qualifications were denying opportunity to pupils with talent in individual subjects who were less successful in others (especially in foreign language requirements). Indeed, the Higher School Certificates had attempted to ensure that pupils followed a sufficiently broad and balanced curriculum by requiring candidates to achieve the minimum standard in a range of subjects for a pass. Dolton and Vignoles (2002) examine the effect of choosing a broader set of courses in secondary school in the United Kingdon.
} 
subjects to gain acceptance into university. ${ }^{18}$ More recently, Advanced Highers and Higher Still certifications have been introduced to provide the opportunity for further specialization in secondary school. However, universities continue to use Highers as the primary basis for admission and there is little doubt that the Scottish system of secondary education provides a broader curriculum than the English one. Again, the reasons for these differences in secondary school curriculum can be traced to historical antecedents. In effect, specialization trickled down from the universities to secondary schools. Moreover, the early influence of English universities on secondary school leaving exams was far stronger than that of Scottish universities since Scottish secondary school leaving certificates had to be approved by the Scottish Education Department.

The difference in the timing of specialization between the English and Scottish systems of undergraduate education does not arise at the graduate level. Graduate degrees in both England and Scotland require admission to a specific course of study. As a result, comparisons between England and Scotland at the graduate level can serve as an important "placebo test," after accounting for initial differences due to undergraduate specialization. These comparisons are explored further in Section 5. The discussion above has focused on England and Scotland but Britain also includes Wales, which has a distinct system of higher education. However, in contrast to Scotland, undergraduate students in Wales apply to a specific course of study in similar fashion as in England. Hence, though we will exclude Wales from the main empirical analysis, comparisons between England and Wales at the undergraduate level can also serve as a useful "placebo test".

\section{Data and Empirical Strategy}

\subsection{Data}

Data for the empirical analysis come from two sources: the Universities Statistical Record (USR) and the 1980 National Survey of Graduates and Diplomates (NSGD). The USR consists of administrative data on all students in British universities undertaking courses of one academic year or longer between 1972-1993: almost 1.9 million undergraduates and over 1 million graduate students. ${ }^{19}$ For

\footnotetext{
${ }^{18}$ These Scottish qualifications evolved directly from the earlier Leaving and Intermediate Certificates which required proficiency over a group of subjects rather than in single subjects.

${ }^{19}$ Excluded are students enrolled in the Open University, Cranfield University, the independent University of Buckingham, and the former polytechnics and central institutions which obtained university status from 1992 onwards.
} 
the most part, we shall focus on students who completed their degree in 1980 to correspond with the data from the NSGD. These administrative data include detailed background information on demographic characteristics and entry qualifications in addition to information related to the degree attained. This is supplemented by information on the occupation, industry and location of the job held in the first year following graduation. The NSGD contains information obtained from a national postal survey of some 8,000 graduates undertaken in 1986/7 by the British Department of Employment. It includes a random sample of one in six university graduates in $1980 .{ }^{20}$ The NSGD contains information about their 1980 qualification, their subsequent labor market experience (occupation, industry, and wages for first and current jobs) and further educational pursuits. There is also information about their high school examination results and some questions regarding satisfaction with their 1980 qualification. Although it is not possible to identify specific universities in the NSGD, there is information on whether students took English or Scottish secondary school leaving exams.

Note that neither dataset is representative of the overall population. Therefore, we might be concerned that the English and Scottish samples of university graduates may not be comparable because of differing participation rates. Using two nationally representative datasets which include all individuals born in Great Britain during one week in 1958 and 1970 (the National Child Development Study and British Cohort Study respectively), I calculated the percentage of individuals that have attained a first degree from university by age 26 . In both of these datasets, the participation rates to university are remarkably similar between England and Scotland: 8\% of the 1958 cohort and $12 \%$ of the 1970 cohort. $^{21}$

Table 1 reveals that the average characteristics of those attending English and Scottish universities are quite similar in both the USR and NSGD. Summary statistics are shown for the sample of students used in the regression analysis. There is a slightly larger percentage of women and married students in Scottish universities. The average age upon completion of the first degree is almost equivalent in England and Scotland but the average duration of the degree is somewhat longer in Scotland. And although the average age that students begin university is slightly lower in

\footnotetext{
${ }^{20}$ The NSGD also includes one in four graduates from other institutions (polytechnics, colleges of education) but I exclude them from the present analysis. Engineering students in Scottish universities are oversampled in the NSGD. Consequently, it is particularly important to control for fields of study with the NSGD sample.

${ }^{21}$ The oft-mentioned higher participation rate in Scotland usually includes students enrolled in non-university higher education institutions, such as polytechnics and colleges of education.
} 
Scotland, the median age of students during their first year in university is 19 for both England and Scotland (not shown). The raw GPA scores shown in Table 1 are converted from letter grades in the A-level and Scottish Higher school leaving examinations. In the regression analysis, these scores are normalized within nation so that coefficients represent the effect of a one standard deviation increase in GPA. Honors level is a measure of success at university ranging from 0 (no honors) to 4 (highest honors) based on the class of degree awarded and standardized across nations. For this sample, almost all students successfully complete their degree (due to rounding). As expected, there are striking differences in the likelihood that students change their major field of study in university. ${ }^{22}$ If we exclude the handful of English universities which allow for some limited switching across related fields, the probability of switching for English students drops to less than $4 \%$.

Table 2 indicates that the composition of broad fields of study across the two nations is not too dissimilar. Nevertheless, relatively more students in Scotland study life sciences, health sciences, and business and relatively fewer study mathematical and social sciences. The composition of occupations across the two nations is also largely comparable. As expected, the majority of students in both England and Scotland enter employment in the UK. The lower rate of unemployment among Scottish individuals is a consequence of the oversampling of engineering graduates who are less likely to be unemployed than others. Note that some individuals do work concurrently while pursuing further study in the UK. Finally, results from the IEA Third International Mathematics and Science Study (TIMSS) in 1994-95 indicate no significant differences between England and Scotland in the mathematics achievement for students in fourth and eighth grade. ${ }^{23}$

The model introduces an important distinction between individuals who enter an occupation that is related to their field of study and those who switch to an unrelated occupation. I construct a variable $S W I T C H$ that captures field switching by grouping fields of study and occupations into categories (see the Data Appendix for more details). As shown in Appendix Table 1, I allow for three levels of classification: narrow (42 categories), broad (12 categories), and very broad (6 categories). Individuals are said to switch to an unrelated occupation when the field of study of their degree and their occupational field are in different categories, subject to the level of classification.

\footnotetext{
${ }^{22}$ Using the USR, I can record changes to the major field of study by observing that the field of study upon entering university is different from the field of study in the degree awarded. In Scottish universities, students are coded with the broad faculty to begin with and changed appropriately when they select a specific field.

${ }^{23}$ There are, however, some differences in the science achievement scores. English students in the eighth grade do somewhat better than their Scottish counterparts but there is no significant difference for fourth graders.
} 
Therefore, $S W I T C H$ is defined as 1 if the occupational field is different from the field of study at university, and 0 otherwise. ${ }^{24}$ Broader classifications indicate lower rates of field switching since only drastic changes from fields of study to occupational fields will register. But the rate of field switching is substantially lower in Scotland than in England according to all classifications. For example, in terms of the broad classification, the rate of field switching in Scotland is between 10 and 20 percentage points lower than the rate of field switching in England. Most of the empirical analysis will focus on the broad classification of fields. ${ }^{25}$

Using data from the USR, Figure 3 plots the rates of field switching, unemployment, and the continuation of further studies following graduation from 1973-1993 as well as the proportion of students who change a major field of study while in university. The raw differential in field switching between England and Scotland is persistent over time. On the other hand, the rates of unemployment and further study are very similar across England and Scotland for most years. Interestingly, the recessions in the early 1980s and early 1990s appear to be associated with an increase in the rate of field switching.

\subsection{Empirical Strategy}

The base sample includes all individuals aiming to attain a BA degree in 1980 and employed fulltime in the first year following completion of their qualification. I exclude individuals pursuing graduate studies while working because this may select for weaker students who need to work while pursuing higher degrees. Using the USR, I verify that the main results hold for other years as well. Using the NSGD, I check whether the main results continue to hold 6 years after entry into the labor market. Furthermore, I explore a variety of alternative sampling restrictions: (i) including graduate students who have occupation data, (ii) including unclassified occupations such as manual and clerical occupations instead of coding them as switches since individuals in one nation may be more likely to end up in non-professional occupations, (iii) coding individuals who end up

\footnotetext{
${ }^{24}$ For example, an individual that studies physics at university will have their field of study coded as "physics" according the narrow classification, "physical sciences" according to the broad classification, and "mathematical, computer, and physical sciences" according to the very broad classification. If this individual is employed as a computer programmer, the occupational switch variable will take on a value of 1 according to the narrow and broad classifications and a value of 0 according to the very broad classification. Individuals studying combined fields are recorded as switches if not employed in any of the fields mentioned.

${ }^{25}$ These include: Math/Computer Sciences, Physical Sciences, Architecture, Engineering, Biological Sciences, Health, Social Services, Social Sciences, Business, Law, Education, and Arts.
} 
unemployed as switches since this may be the result of a differential macroeconomic shock across the two nations, and (iv) excluding the fields of education and business or coding individuals who study them as non-switches since they are particularly subject to misclassification (and similarly with combined fields). Additional robustness checks restrict the sample to students with top high school grades who are clearly free to choose their fields, unconstrained by admissions requirements and the availability of slots. Finally, I also try to focus on the sample of English students from northern England since they are probably most similar to individuals from Scotland.

The effect of a Scottish degree on the probability of switching is captured by $\lambda$ in the following regression equation:

$$
S W I T C H_{i j}=\beta^{\prime} \mathbf{X}_{i j}+\lambda S C O T_{i j}+\phi_{j}+\varepsilon_{i j}
$$

where $S W I T C H_{i j}$ is a dummy variable for a field switch for individual $i$ in field $j, S C O T_{i j}$ is a dummy variable indicating the individual received a Scottish degree and therefore specialized late, $\phi_{j}$ is a set of field of study effects, $\mathbf{X}_{i j}$ are demographic characteristics, and $\varepsilon_{i j}$ is a disturbance term. The primary demographic controls include sex, age, marital status, high school GPA, and parent's socioeconomic status. In further robustness checks, I also show results from regressions run separately by field of study, and two "placebo tests" where $W A L E S_{i j}$ or $S C O T G R A D_{i j}$ are used in place of $S C O T_{i j}$ to explore comparisons between England and Wales or England and Scotland at the graduate level.

Note, however, that attainment of a Scottish or English degree is not randomly assigned. Rather, once they complete their secondary education, individuals can choose to attend universities in either England or Scotland. Table 2 shows the national breakdown of individuals studying in England and Scotland. The migration patterns from prior residence to university indicate that 3.3 percent of individuals with English prior residence choose to study in Scotland while 7.4 percent of individuals with Scottish prior residence choose to study in England. ${ }^{26}$ There may be systematic differences between those individuals that decide to attend university in an alternative regime. If these differences are uncorrelated with the probability of switching, this should not pose a problem. However, if individuals who migrate to university have a different likelihood of switching, OLS estimates will be biased. This might arise because individuals who migrate have unobserved characteristics which

\footnotetext{
${ }^{26}$ Note that, since England is much more populous, the $3.3 \%$ of English individuals that study in Scotland make up over $18 \%$ of the student body in Scottish universities.
} 
are correlated with the likelihood of switching. Or more directly, individuals might choose a regime based on their own expected likelihood of switching. For example, individuals from England that have less precise priors on match quality may decide to attend universities in Scotland where academic specialization is postponed. Hence, I will also consider regressions in which I instrument for the attainment of a Scottish or English degree with the region of prior residence. Since the type of degree and region of prior residence are not available in the NSGD, I use the type of school leaving examinations (whether Scottish or English) to estimate a reduced form equation of the probability of field switching. ${ }^{27}$

\section{Results}

The main predictions on field switching are examined with both the USR and NSGD in Tables 3, 4 and 5. Across almost all specifications, the probability of a field switch is significantly lower for individuals with Scottish degrees than for their English counterparts. The estimated difference in field switching between England and Scotland from the preferred 2SLS specification is approximately 6 percentage points, which is substantial considering that the rate of field switching in Scotland is about .42. Indeed, the coefficient on SCOT from equation 1 is negative and significant in almost every year between 1973 and 1993 (results not shown, but Panel A of Figure 3 displays the raw differences over time). According to the model, these findings indicate that the return to match quality is high relative to the return to specific skills. That we observe a higher incidence of switching in England, a regime with early specialization, implies that the benefits to increased match quality are substantial, and, indeed, large enough to outweigh the greater loss of skills.

\subsection{Main findings}

Using data from the USR, Table 3 shows the pattern of field switching for students who graduated in 1980. As a baseline, Panel A includes all English students. All regressions include controls for gender, marital status, age, high school GPA, and parental SES. In column (1), I estimate the difference in the probability of field switching between England and Scotland without controlling for

\footnotetext{
${ }^{27}$ While there is some choice available with the type of secondary school, through boarding school perhaps, it is undoubtedly much less than in university (the correlation between Scottish residence and attendance in Scottish high school is .96). Furthermore, few secondary schools in Scotland offer English leaving examinations (the correlation between attendance in a Scottish high school and sitting Scottish leaving examinations is .98).
} 
fields of study or region of work. Once I control for the composition of fields across nations in column (2), the estimated differential in field switching declines substantially. In other words, not only do individuals in Scotland switch less, but they also tend to study fields which are associated with less switching. ${ }^{28}$ In column (3), I add controls for region of work and the coefficient on SCOT becomes smaller still, suggesting that there may be less switching among Scottish employers who prefer to hire individuals with related qualifications. However, this specification needs to be interpreted with care since the decision to work in England or Scotland is probably endogenous; individuals who decide to switch may also make systematically different decisions about where they wish to work.

In columns (4), (5) and (6), I instrument for the attainment of a Scottish degree with the region of prior residence. ${ }^{29}$ 2SLS estimates of the difference in field switching between England and Scotland increase substantially and lend support to the hypothesis of non-random selection: If individuals who are less focused and hence more likely to switch decide to get their degrees in Scotland, OLS estimates of field switching in Scotland will be biased towards more switching. Similarly, if individuals who are more focused and less likely to switch decide to get their degrees in England, OLS estimates of field switching in England will be biased towards less switching. Since individuals with Scottish degrees are, in fact, less likely to switch than their English counterparts, 2SLS estimates should and do indicate an even greater differential in field switching. Panel B uses information from the USR to restrict the sample of English students to those from northern England since they are the most convincing comparison group to individuals from Scotland. ${ }^{30}$ The pattern of field switching between Scotland and northern England appears to be even stronger than one found when all students from England are included. Results are also unchanged when we exclude students at Oxford and Cambridge (not shown). The main robustness checks for field switching described in the previous section are shown in Appendix Table 2. In particular, our findings remain when using alternative classifications and restricting to the sample of students with top high school

\footnotetext{
${ }^{28}$ In fact, English students may be endogenously choosing broader fields which facilitate switching to avoid specializing in an excessively narrow field. Much of the variation in field switching is explained by differences across fields of study (the $R^{2}$ increases from .03 to .39 once controls for fields of study are included).

${ }^{29}$ Coefficient estimates are almost equivalent when instrumenting for attainment of a Scottish degree with the type of secondary school leaving exams completed (English A-levels or Scottish Highers) or with the location of secondary school (England or Scotland).

${ }^{30} \mathrm{On}$ this final sample restriction, I also consider whether there are different migration patterns for work in London from Northern England as compared to Scotland. However, I find that few individuals from either region (approximately $5 \%$ from each) migrate to London for work. Note, this result emerges from a different dataset (National Survey of Graduates 1985/90) since neither the USR or NSGD contains detailed regions of work and origin.
} 
GPAs.

Table 4 examines field switching within the field of engineering. A degree in engineering is associated with a well-defined occupation and the content of such degrees is extremely similar across the two nations. Using the narrow classification we can identify field switches by subfield; i.e. from studying mechanical engineering to becoming an electrical engineer. In order to increase precision, we pool the USR data on engineers from 1980 to $1992 .{ }^{31}$ The main results are confirmed in this setting: Individuals who study engineering in Scotland are generally less likely to switch to an unrelated occupation than their counterparts who study engineering in England. Appendix Table 3 shows the likelihood of switching in each field of study using USR data pooled from 1980 to 1992. The coefficient on $S C O T$ for social sciences and the arts is negative and significant, indicating that this differential is also associated with fields outside the hard sciences (where switching out may be easier). Not surprisingly, there are no significant differences in field switching across England and Scotland for certain fields such as health, business, and education. The degree in medicine is an extremely specialized course in both English and Scottish institutions. And both education and business provide a very broad set of skills that may dampen the differences which usually arise from early versus late specialization. ${ }^{32}$

Table 5 uses data from the NSGD to examine field switching between England and Scotland. We estimate a reduced-form equation where $S C O T$ is a dummy variable identifying whether students took English or Scottish secondary school leaving exams, because that is the only indicator available in the NSGD. As a result, we cannot restrict the sample to individuals from northern England. Again, all regressions include controls for gender, marital status, age, high school GPA, parental SES. Columns (1), (2) and (3) show the reduced-form effect of having completed school leaving exams in Scotland on the likelihood of working in an occupation unrelated to the chosen field of study in the first year following graduation. Confirming our results from the USR, most specifications show that students from England are more likely to switch fields than their counterparts from Scotland. However, the NSGD also contains information on student outcomes six years following the completion of their degree. Columns (4), (5), and (6) indicate that the differential

\footnotetext{
${ }^{31}$ Note that we exclude 1973-1979 and 1993 because there is no information on parental SES. We get similar results if we include these years and drop the measures of SES.

${ }^{32}$ More generally, estimates of differences in occupational switching between England and Scotland may vary across fields because of differing relative returns to match quality. Learning about match quality may be more important in certain fields than in others.
} 
in field switching between England and Scotland remains after six years. Even stronger results are obtained if we consider all individuals employed six years following completion of the BA degree by including those who were not employed in the first year after completing their degree (results not shown).

\subsection{Two "placebo experiments"}

In addition to the various robustness checks discussed above, Table 6 presents two "placebo tests" to verify that the differential in field switching between England and Scotland is not due to differences in unobserved characteristics across the two nations. Panel A examines the difference in switching between England and Wales for 1980 college graduates using data from the USR where we can identify whether individuals attended university in Wales. Since undergraduate students in both England and Wales apply to a specific field of study in university, we would expect no difference in field switching between England and Wales. The specifications are analogous to those in Panel A of Table 3. Columns (1), (2) and (3) report the results from OLS regressions where WALES is a dummy variable indicating whether individuals completed university in Wales. Columns (4), (5) and (6) show results from the 2SLS regressions where the attainment of a Welsh degree is instrumented with the region of prior residence. None of the specifications indicate any significant difference in field switching between England and Wales. Since the timing of academic specialization in Wales is identical to that of England, the absence of a difference in field switching between England and Wales is reassuring and supports the contention that the difference in field switching between England and Scotland is a consequence of the timing of specialization.

Panel B examines the difference in field switching between England and Scotland, but at the graduate level. Since graduate degrees in both England and Scotland are similar in terms of specialization - both require admission to a very specific field of study - we expect to see no difference in field switching at the graduate level. Of course, we must control for undergraduate degree since the model itself predicts that students who complete an undergraduate degree in Scotland will have higher match quality and lower specific skills than those in England. The USR has separate files containing information on students with graduate degrees. We focus on the sample of students who completed their studies in 1980 and therefore entered the labor market at the same time as the undergraduate students discussed above. Columns (1), (2) and (3) report 
results from the OLS regressions where $S C O T G R A D$ is a dummy variable indicating whether individuals completed their graduate degrees in Scotland. ${ }^{33}$ Controlling for undergraduate degree, there is no significant difference in the probability of field switching between England and Scotland at the graduate level. The NSGD includes students who graduated from college in 1980 and completed their graduate degrees some years later. Columns (4), (5) and (6) report results from the reduced form regression where the completion of graduate degrees in Scotland is proxied by whether students took English or Scottish secondary school leaving exams - unfortunately, we cannot control for undergraduate degree in these regressions. Still, there is no significant difference in field switching between England and Scotland at the graduate level. These results further support the argument that the difference in field switching between England and Scotland derives from the timing of specialization in undergraduate education and not from some other characteristic inherent to English and Scottish individuals, or from labor market conditions particular to England and Scotland. ${ }^{34}$

\subsection{Alternative explanations for field switching}

Field switching may arise for reasons other than those described by a model of academic specialization. If certain individuals are particularly indecisive, they may be more likely to experience field switching. Other individuals may simply be more adept at making changes and therefore more likely to switch to an occupation unrelated to their field of study. While these characteristics are generally unobservable, I can examine whether field switching is correlated with other decisions, such as a change in major field of study in university. Regression analysis confirms that individuals who change fields of study during university are also significantly more likely to experience a field switch (not shown). But according to the USR sample of 1980 graduates, 18 percent of Scottish students change their field of study during university compared to just 7 percent of the English

\footnotetext{
${ }^{33}$ The USR does not contain information on birth region so we cannot instrument for whether an individual attained a Scottish degree with their place of birth or place of residence prior to commencing their studies.

${ }^{34}$ I also examine the probability of switching to a graduate degree in a field that is unrelated to the undergraduate field of study - "academic switching". The probability of switching to an unrelated graduate degree is generally not significantly different for individuals with a Scottish undergraduate degree than for individuals with an English undergraduate degree (results not shown). Indeed, the sign is actually positive in some cases. One possible explanation is that the relative return to match quality for success in further study is different than for wages in the labor market. If further study at the graduate level puts more emphasis on the specific skills acquired at the undergraduate level than a job in the same occupational field, the benefits from switching may no longer exceed the greater loss of skills in the early regime. In other words, the relative return to academic skills in graduate education may be substantially larger than that in the job market.
} 
students (see Panel B of Figure 3 for a graph of this differential across all years). That students in Scotland are more likely to change their declared field of study after entry into university is strong evidence that the differential in field switching between England and Scotland is not driven by a lower propensity to make changes in Scotland.

Field switching may also be driven by the availability of jobs in different occupational fields. If certain sectors suffer shocks to labor demand, recent graduates may be forced to switch to a different occupational field from the one they studied. Appendix Table 4 shows the percentage of individuals employed in different occupational fields by field of study in 1980. As expected, certain fields of study have substantial outflows into unrelated occupational fields (social sciences, physical sciences, and arts). Other occupational fields have substantial inflows from unrelated field of study (business, engineering, education). However, evidence for flows in both directions - for example, from math/computer sciences to physical sciences and vice versa - suggests that field switching is not driven solely by the availability of jobs in different occupational fields.

\subsection{Variation in field switching across universities}

A comparison of labor market outcomes across England and Scotland has the disadvantage of including only two nations. An alternative approach could have been to compare student outcomes across universities. The model assumed that the cost to switching majors in university following specialization was infinite and identical across all universities within each regime. But in fact, there is some variation across institutions. In England, although almost all universities require students to apply to a specific field prior to entry, there are differences in the penalty to changing fields of study once students are enrolled in a specific course. Some universities require students who switch fields of study to start university anew while others allow for limited switching across related fields. In Scotland, students are either required to write down their expected field of study or they are coded with a broad faculty to begin with and changed appropriately when they select a specific field. Since these penalties are difficult to quantify, we might consider using the actual proportion of students that change fields as a proxy for the penalty.

However, any comparison across universities will suffer from selection bias as students choose among the many universities available to them. We expect individuals who are unsure about what

to study to be more likely to choose a university with less stringent penalties and also be more likely 
to switch to an unrelated occupation upon entering the labor force. Moreover, using the actual proportion of students that change fields as a proxy may well confound the actual penalty with student characteristics that are correlated with these changes and other labor market outcomes. Indeed, if students who switch fields are also more likely to switch to unrelated occupations, then any unequal distribution of students across universities will yield this correlation. Figure 4 plots the proportion of individuals who switch to an unrelated occupation by the proportion of students that change fields of study while in university. The positive correlation for both England and Scotland would mistakenly suggest that students attending universities with less stringent penalties for specializing later are also more likely to switch to an unrelated occupation - a rather different result from the one we reached by comparing across nations. Thus, selection bias is a serious problem if we don't consider exogenous differences in the timing of specialization. Note that Figure 4 also reveals evidence for the findings between England and Scotland. That most of the points representing Scottish universities lie below the English ones confirms that individuals in Scotland are less likely to switch to an unrelated occupation.

\section{Conclusion}

Substantial research has examined the effect of education on labor market outcomes. Recent work has confirmed that the relationship between education and outcomes such as wages is indeed causal. ${ }^{35}$ However, there has been less progress in understanding why education affects labor market outcomes. Education is often thought to provides certain skills that make workers more productive in performing tasks that are valued in the labor market. ${ }^{36}$ Alternatively, education may enhance workers ability to deal with disequilibria which may result from technological change. ${ }^{37}$ This paper examines another important mechanism for why education might improve labor market outcomes. By providing valuable information about talents and tastes, education may help individuals match more successfully to different occupational fields.

I develop a model of specialization in which individuals, by taking courses in different fields

\footnotetext{
${ }^{35}$ See Card (1999) for a survey of the recent literature on returns to schooling.

${ }^{36}$ There is evidence that education can improve skills, as measured by the Armed Forces Qualifying Test (AFQT); see Neal and Johnson (1996) and Cascio and Lewis (2006).

${ }^{37}$ Nelson and Phelps (1966) show that greater technological change may raise the return to education while Bowles (1970) interprets the ability of dealing with disequilibria within the context of migration.
} 
of study, accumulate field-specific skills and receive noisy signals of match quality in these fields. Distinguishing between educational regimes with early and late specialization, I derive a comparative static prediction regarding the probability of switching to an occupation unrelated to one's field of study. If higher education serves mainly to provide specific skills, the model predicts more switching in a regime with late specialization because the cost of switching is lower in terms of foregone skills. On the other hand, if higher education serves mainly to provide valuable information about match quality, switching may be higher in a regime with early specialization because the benefits from higher expected match quality from switching will outweigh overwhelm the greater loss of specific skills. Testing these predictions across British systems of higher education, I find that individuals in the Scottish system, where specialization occurs relatively late, are less likely to switch to an unrelated occupation than their counterparts in England, who specialize early. No such differential is observed at the graduate level or between England and Wales where the systems coincide in the timing of specialization. Hence, observing a higher probability of switching a regime with early specialization, such as England, implies that the return to match quality is sufficiently high to overwhelm the greater loss of skills.

The notion that people switch to different fields in order to correct for choices made in the past is a central feature of this paper. Clearly, there are other reasons why individuals may end up working in occupations that are unrelated to their fields of study. So simply observing that field switching takes place is not sufficient evidence that education provides valuable information about match quality. However, by exploiting the exogenous difference in the timing of academic specialization across two systems of higher education, we can take advantage of a simple comparative static prediction to test for the importance of such information. Moreover, focusing on the likelihood of switching is particularly useful since the decision to switch to an unrelated occupation encompasses non-pecuniary as well as pecuniary considerations. The findings in this paper confirm that education is important, not only in providing specific skills that are useful in the labor market, but also in helping students learn about their own tastes and talents. 


\section{References}

Altonji, J.G. (1993): "The Demand for and Return to Education When Education Outcomes Are Uncertain," Journal of Labor Economics 11(1), 48-83

Arcidiacono, P. (2004): "Ability Sorting and the Returns to College Major," Journal of Econometrics, 121(1-2), 343-375

Bowles, S. (1970): "Migration as Investment: Empirical Tests of the Human Investment Approach to Geographical Mobility," The Review of Economics and Statistics 52 (4), 356-362.

Card D. (1999): "The Causal Effect of Education on Earnings," Handbook of Labor Economics, Vol 3, 1801-1863

Cascio, E. and E. Lewis (2006): "Schooling and the Armed Forces Qualifying Test: Evidence from School-Entry Laws," Journal of Human Resources 41(2), 294-318.

DeGroot, M. H. (1970): Optimal Statistical Decisions. McGraw-Hill Company

Evans, K. (1975): The Development and Structure of the English Educational System. University of London Press

Gupta, S.S. and K.J. Miescke (1996): "Bayesian look ahead one-stage sampling allocations for selection of the best population," Journal of Statistical Planning and Inference 54, 229-244

Gupta, S.S. and K.J. Miescke (1994): "Bayesian look ahead one stage sampling allocations for selecting of largest normal mean," Statistical Papers 35, 169-177

Hunter, S.L. (1971): The Scottish Educational System. Oxford: Pergamon Press

Hvide, H.K. (2003): "Education and the Allocation of Talent," Journal of Labor Economics 21(4), 945-976

Johnson, W.R. (1978): "A Theory of Job Shopping," Quarterly Journal of Economics 92(2), 261-278

Johnson, W.R. (1979): "The Demand for General and Specific Education with Occupational Mobility," Review of Economic Studies 46(4), 695-705

Jovanovic, B. (1979): "Job Matching and the Theory of Turnover," Journal of Political Economy $87(5), 972-990$

Jovanovic, B. and Nyarko Y. (1997): "Stepping Stone Mobility," Carnegie-Rochester Conference Series on Public Policy 46, 289-326

Malamud, O. and C. Pop-Eleches (2007): "General Education versus Vocational Training: Evidence from an Economy in Transition," mimeo.

McCall, B. (1990): "Occupational Matching: A Test of Sorts," Journal of Political Economy 98(1), 45-69

McMillen, D.P., Seaman, P.T., L.D. Singell (2007): "A Mismatch Made in Heaven: A Hedonic Analysis of Overeducation and Undereducation," Southern Economic Journal 73(4): 901-930 
Miescke, K.J. (1999): "Bayes sampling designs for selection procedures". Invited chapter in: Multivariate, Design, and Sampling, S. Ghosh ed., M. Dekker, New York, 93-117.

Miller, R. (1984): "Job Matching and Occupational Choice," Journal of Political Economy 92(6), $1086-1120$

Neal, D. (1999): "Complexity of Job Mobility among Young Men," Journal of Labor Economics $17(2), 237-261$

Neal, D. and W.R. Johnson (1996): "The Role of Premarket Factors in Black-White Wage Differences," Journal of Political Economy 104(5), 869-895

Nelson, R.R. and E.S. Phelps (1966): "Investment in Humans, Technological Diffusion, and Economic Growth," American Economic Review, 69-75

Osborne, G.S. (1967): Scottish and English Schools: A comparative survey of the past fifty years. University of Pittsburgh Press

Schultz, T.W. (1968): "Resources for Higher Education: An Economist's View," Journal of Political Economy 67(3), 327-347

Shaw, K.L. (1987): "Occupational Change, Employer Change, and the Transferability of Skills," Southern Economic Journal 53, 702-719

Sicherman N. (1991): "Overeducation in the Labor Market," Journal of Labor Economics 9(2), 101-123

Spence, M. (1973): “Job Market Signaling," Quarterly Journal of Economics 87, 355-374

Squires, G. (1987): "The Curriculum," British Higher Education (ed. Tony Becher). London: Allen \& Unwin

Trow, M. (1999): "From Mass Higher Education to Universal Access: The American Advantage" Minerva 37, 1-26

University of Edinburgh: 2003 Undergraduate Prospectus 


\section{A Data Appendix}

Complete documentation for the Universities' Statistical Record, 1972/73-1993/4: Undergraduate Records, Postgraduate Records and the National Survey of 1980 Graduates and Diplomates, 19861987 are available from the UK Data Archive: http://www.data-archive.ac.uk. Details of the variables constructed for this study are described as follows:

\section{Field switch}

A field switch is defined as a binary variable that takes on a value of 1 if an individual is employed in an occupation that is unrelated to his major field of study at the undergraduate level, and 0 otherwise. In order to determine whether an individual is employed in an occupation that is related or unrelated to his field of study, I group fields of study and occupations into categories. As shown in Appendix Table 1, I allow for three gradations of classification: narrow (42 categories), broad (12 categories), and very broad (6 categories). Occupations and fields of study are coded according to each of the alternative classifications. Where the occupation and field of study are classified in different categories, the field switch variable takes on a value of 1 . For example, an individual that studies physics at university will have their field of study coded as "physics" according the narrow classification, "physical sciences" according to the broad classification, and "mathematical, computer, and physical sciences" according to the very broad classification. If this individual is employed as a computer programmer, the field switch variable will take on a value of 1 according to the narrow and broad classifications and a value of 0 according to the very broad classification. Combined fields are considered switches if the individual is not employed in any of the fields mentioned.

\section{Degree Honors}

There is some variation in honors classifications among universities in general, and between Scottish and English institutions in particular. Hence, I aggregate honors levels into roughly comparable categories. The honors variable takes on the value of 4 for a 1st, unclassified, and enhanced degree class, 3 for upper 2nd, undivided 2nd degree class, and ordinary, 2 for lower 2nd, Aegrotata, and Pass, and 1 for 3rd, 4th and General degree class.

\section{High school GPA}

Scores on secondary school leaving exams are officially coded as letter grades (A, B, C, etc.). These are converted into numerical scores where $\mathrm{A}=10, \mathrm{~B}=8, \mathrm{C}=6, \mathrm{D}=4$, and $\mathrm{E}=2$. Average scores are then standardized by nation and combined so that the overall distribution of high school GPA has mean 0 and standard deviation 1.

\section{SES}

Individual SES scores are based on parental occupations as follows: 0-unstated, retired, or unknown, 1-professionals workers, 2-intermediate workers, 3-skilled non-manual, 4-skilled manual, 5-partially skilled, 6-unskilled, and 7-unemployed.

\section{Region of Work}

Region of work is classified as England, Scotland, Wales, Northern Ireland or abroad in the USR. Region of work is classified as London, Southern England, Midlands, East Anglia, Northern England, Wales, Scotland, Northern Ireland or abroad in the NSGD.

\section{Industry}

Industry are classified according to broad SIC codes: Agriculture, Forestry, and Fisheries (0), Mining (1), Mineral Extraction and Production (2), Heavy Manufacturing (3), Light Manufacturing (4), Construction (5), Wholesale and Retail Trade (6), Transportation, Communication, and Public Utilities (7), Financial and Business Services (8), Professional and Related Services (9) 


\section{B Mathematical Appendix}

The mathematical appendix provides a formal treatment of the model of academic specialization presented in the main text. For ease of exposition, the structure of the appendix and most of the notation parallels the main text.

\section{Formal Setup}

Suppose $N$ courses are taken in $k \geq 2$ fields of study. Let $F_{1}, \ldots, F_{k}$ be normal populations associated with fields of study $i=1, \ldots, k$, each with unknown mean $\theta_{1}, \ldots, \theta_{k}$ and a common known variance $\sigma^{2}>0$. The unknown means $\theta_{1}, \ldots, \theta_{k}$ represent unobserved match quality in each field.

\section{Sequence of observations}

In Stage 1, $n$ observations from each population $P_{i}$ are observed. These correspond to observations on match quality from courses taken in each field of study prior to specialization. The sample means of these observations, $X_{i}$, are independent and distributed $N\left(\theta_{i}, p^{-1}\right)$ with $p=n \sigma^{-2}$. In Stage 2 , one population, $i^{*}$, is selected for further sampling and $(N-n k)$ additional observations are observed from this population. These correspond to observations on match quality in the chosen field from courses taken following specialization. The sample mean of the second set of observations, $Y$, is distributed $N\left(\theta_{i^{*}}, q^{-1}\right)$ with $q=(N-n k) \sigma^{-2}$ and where $\theta_{i^{*}}$ is the (unknown) mean of the population chosen after Stage $1 .{ }^{38}$

Beliefs on match quality

Belief about match quality $\theta_{1}, \ldots, \theta_{k}$ are represented by the parameters $\widehat{\theta}_{1}, \ldots, \widehat{\theta}_{k}$. These parameters are random and follow independent and identical prior distributions assumed to have $\widehat{\theta}_{i} \sim N\left(\mu, \nu^{-1}\right)$ with $\nu=\sigma_{0}^{-2}$. The conditional distribution of $\widehat{\boldsymbol{\theta}}$ at each stage can be expressed as follows:

$$
\begin{aligned}
& \widehat{\theta}_{i} \quad \mid \quad \mathbf{X}=\mathbf{x} \sim N\left(\frac{p x_{i}+\nu \mu}{p+\nu},(p+\nu)^{-1}\right), \quad i=1, \ldots, k \text { independent } \\
& \widehat{\theta}_{i} \quad \mid \quad \mathbf{X}=\mathbf{x}, Y=y \sim N\left(\frac{\pi \mu_{i}(\mathbf{x})+q_{i} Y}{\pi+q},\left(\pi+q_{i}\right)^{-1}\right), \quad q_{i^{*}}=q \text { and } 0 \text { otherwise }
\end{aligned}
$$

where $\pi=p+\nu$ represents the relative combined (prior plus sampling) information gained from field $F_{i}$, and where $\mu_{i}(\mathbf{x})=\left(p x_{i}+\nu \mu\right) /(p+\nu)$ represents the estimated mean of field $F_{i}$ after Stage 1. In terms of the notation in the main text, $\mu_{i}^{\prime}=\mu_{i}(\mathbf{x})$ and $\mu_{i}^{\prime \prime}=\mu_{i}(\mathbf{x}, y){ }^{39}$

\section{Payoffs}

The returns associated with field $F_{i}$ is denoted by $u_{i}=\alpha \theta_{i}+\beta s_{i}$ where $s_{i}$ is the cumulative number of observations from field $F_{i}$. This return represents the wage received in field $i$ upon entering the labor market. In terms of the model of academic specialization, $\alpha$ is the return to match quality and $\beta$ is the return to specific skills. Note that we can express the loss function associated with population $F_{i}$ as $L_{i}(\boldsymbol{\theta}, s)=-\alpha \theta_{i}-\beta s_{i}{ }^{40}$

\section{Decision rules}

\footnotetext{
${ }^{38}$ Since $X_{i}$ and $Y_{i^{*}}$ already correspond to the mean of the samples, we will use $x_{i}$ and $y_{i^{*}}$ instead of $\bar{x}_{i}$ and $\bar{y}_{i^{*}}$.

${ }^{39}$ Note also that the conditional distribution of $Y$ given $\mathbf{X}=\mathbf{x}$ is distributed $N\left(\mu_{i}(\mathbf{x}), w\right)$ with $w=(\pi+q) \pi q$.

${ }^{40}$ This corresponds to a linear loss function, $L_{i}(\boldsymbol{\theta}, s)=\theta_{[k]}-\theta_{i}$, where $\theta_{[k]}=\max \left\{\theta_{1}, \ldots, \theta_{k}\right\}$ is normalized to zero and with an additional negative cost associated with the amount of sampling from the population $i$.
} 
After $\mathbf{X}=\mathbf{x}$ has been observed at Stage 1, the Bayes selection rule $i^{*}=d_{1}^{*}(\mathbf{x})$ can be found by minimizing the posterior expected loss (or in our framework, maximizing posterior expected wages):

$$
\begin{aligned}
E_{X}\left(L\left(\widehat{\boldsymbol{\theta}}, d_{1}^{*}(\mathbf{X})\right) \mid \mathbf{X}=\mathbf{x}\right) & =\max _{i=1, \ldots, k} E_{X}\left(\alpha \widehat{\theta}_{i}+\beta s_{i} \mid \mathbf{X}=\mathbf{x}\right) \\
& =\alpha \max _{i=1, \ldots, k} E_{X}\left(\widehat{\theta}_{i} \mid \mathbf{X}=\mathbf{x}\right)+\beta s \\
& =\alpha \max _{i=1, \ldots, k} \mu_{i}(\mathbf{x})+\beta s=\alpha\left(\frac{p\left(\max _{i=1, \ldots, k} x_{i}\right)+\nu \mu}{p+\nu}\right)+\beta s
\end{aligned}
$$

where $s$ corresponds to the specific skills in each field which are equivalent across fields. The optimal selection, $i^{*}$, at Stage 1 will therefore be the population with the largest observed sample mean after Stage 1 since $d_{1}^{*}(\mathbf{x})=\arg \max _{i=1, \ldots, k} x_{i}$. This is intuitive since, with identical prior distributions on match quality, the only distinguishing feature of each population is the information received in Stage 1. Let $x_{[1]}<x_{[2]}<\cdots<x_{[k]}$ denote the order sample means from Stage 1 and $\mu_{[1]}(\mathbf{x})<\mu_{[2]}(\mathbf{x})<\cdots<\mu_{[k]}(\mathbf{x})$ denote the ordered posterior means from Stage 1. Note that, in terms of the notation in the main text, $\mu_{i^{*}}^{\prime}=\mu_{[k]}(\mathbf{x})$ and $\mu_{i^{a}}^{\prime}=\mu_{[k-1]}(\mathbf{x})$.

Similarly, after $Y=y$ has been observed at Stage 2, the Bayes selection rule $i^{* *}=d_{2}^{*}(\mathbf{x}, y)$ will satisfy

$$
E\left(L\left(\widehat{\boldsymbol{\theta}}, d_{2}^{*}(\mathbf{X}, \mathbf{Y})\right) \mid \mathbf{X}=\mathbf{x}, Y=y\right)=\max _{i=1, \ldots, k} E\left(\alpha \widehat{\theta}_{i}+\beta s_{i} \mid \mathbf{X}=\mathbf{x}, Y=y\right)
$$

These Bayes selection rules yield the maximum posterior expected wages, or Bayes risk, of their respective problems in Stages 1 and 2. Let $\mu_{i^{*}}^{\prime \prime}=\mu_{[k]}(\mathbf{x}, y)$ denote the posterior mean of field, $i^{*}$, after Stage 2. An important feature of this decision problem is that the selection $i^{* *}=d_{2}^{*}(\mathbf{x}, y)$ after Stage 2 may differ from the selection $i^{*}=d_{1}^{*}(\mathbf{x})$ after Stage 1 since further observations in Stage 2 may reveal that the initial choice was not as good as initially thought. This corresponds precisely to the possibility of switching fields expressed in the main theoretical framework.

Proof of Proposition 1. The probability of switching can be expressed as follows:

$$
\operatorname{Pr}(\text { switch })=\operatorname{Pr}\left(u\left(\mu_{i^{a}}^{\prime}, s\right)>u\left(\mu_{i^{*}}^{\prime \prime}, s\right)\right) \text { or } \operatorname{Pr}\left(u\left(\mu_{[k-1]}(\mathbf{x}), s\right)>u\left(\mu_{[k]}(\mathbf{x}, y), s\right)\right)
$$

where $u\left(\mu_{i^{*}}^{\prime \prime}, s\right)=u\left(\mu_{[k]}(x, y), s\right)$ is the wage expected in the chosen field based on the beliefs after Stage 2 and $u\left(\mu_{i^{a}}^{\prime}, s\right)=u\left(\mu_{[k-1]}(\mathbf{x}), s\right)$ is the wage expected in the second-best field based on the beliefs after Stage 1. Using the latter notation and since individuals are assumed to be riskneutral, we can write the probability of switching in terms of skills and beliefs about the mean of match quality: $\operatorname{Pr}\left(\alpha \mu_{[k-1]}(\mathbf{x})+\beta n>\alpha \mu_{[k]}(\mathbf{x}, y)+\beta(n+(N-n k))\right)$. We can further decompose $\mu_{[k]}(\mathbf{x}, y)$, into the mean of match quality in the chosen field after Stage $1, \mu_{[k]}(\mathbf{x})$, and the mean of 
the observations taken from the chosen field in Stage $2, Y^{[k]}:^{41}$

$$
\begin{aligned}
\operatorname{Pr}(\text { switch }) & =\operatorname{Pr}\left(\mu_{[k-1]}(\mathbf{x})>\mu_{[k]}(\mathbf{x})+\left(\frac{q}{\pi(\pi+q)}\right)^{1 / 2} Y^{[k]}+\frac{\beta}{\alpha}(N-n k)\right) \\
& =\operatorname{Pr}\left(\left(\frac{q}{\pi(\pi+q)}\right)^{1 / 2} Y^{[k]}<-\frac{p}{p+\nu}\left(x_{[k]}-x_{[k-1]}\right)-\frac{\beta}{\alpha}(N-n k)\right) \\
\text { where } \frac{d}{d n}\left(\frac{q_{i}}{\pi\left(\pi+q_{i}\right)}\right) & <0, \frac{d}{d n}\left(\frac{p}{p+\nu}\right)>0 \text { and } \frac{d}{d n}\left(\frac{\beta}{\alpha}(N-n k)\right)<0
\end{aligned}
$$

The left-hand side term represents new information about match quality in the chosen field revealed in Stage 2; the first term on the right-hand side represents the loss in match quality from switching based on beliefs from Stage 1; the second term on the right-hand side represents the loss in skills from switching to the second-best field. Individuals will switch fields when the new information about match quality is sufficiently negative so as to overwhelm the loss in match quality and skills from switching.

Later specialization corresponds to more observations in Stage 1 which decreases the relative importance of new information in Stage 2, increases the relative importance of information in Stage 1 , and raises the loss in skills associated with switching. When $\beta$ is large relative to $\alpha$, the loss in skills associated with switching will dominate and $\frac{d}{d n} \operatorname{Pr}($ switch $)>0 .{ }^{42}$ When $\alpha$ is large relative to $\beta$, the loss in match quality associated with switching will dominate and $\frac{d}{d n} \operatorname{Pr}($ switch $)<0 .{ }^{43}$ Using numerical methods, we can always find a unique constant $C>0$, so that a regime with early specialization, $n^{E}$, will have a higher probability of switching than a regime with late specialization, $n^{L}$, if $\frac{\alpha}{\beta}>C$ and a regime with late specialization, $n^{L}$, will have a higher probability of switching than a regime with late specialization, $n^{L}$, if $\frac{\alpha}{\beta}<C$.

Proof of Corollary 1. Suppose now that $u\left(\theta_{i}, s_{i}\right)=\alpha \theta_{i}+\beta s_{i}+\epsilon_{i}$ where $\epsilon_{i} \sim N\left(0, \tau^{2}\right)$. Then, if the return to match quality is equal to zero, $\alpha=0$, we can express the probability of switching as follows:

$$
\begin{aligned}
\operatorname{Pr}(\text { switch }) & =\operatorname{Pr}\left(\alpha \mu_{[k-1]}(\mathbf{x})+\beta n+\epsilon_{[k-1]}>\alpha \mu_{[k]}(\mathbf{x}, y)+\beta(n+(N-n k))+\epsilon_{[k]}\right) \\
& =\operatorname{Pr}\left(\beta n+\epsilon_{[k-1]}>\beta(n+(N-n k))+\epsilon_{[k]}\right) \\
& =\operatorname{Pr}\left(\epsilon_{[k-1]}-\epsilon_{[k]}<-\beta(N-n k)\right) \\
& =\Phi\left(\frac{\beta(n k-N)}{\sqrt{2 \tau^{2}}}\right) \quad \text { since } \epsilon_{[k-1]}-\epsilon_{[k]} \sim N\left(0,2 \tau^{2}\right)
\end{aligned}
$$

Assuming that $\sigma^{2}=\infty$ yields the same expression since $p=n \sigma^{-2}=0$ and $q=(N-n k) \sigma^{-2}=$ 0 . Hence, in either case, a larger $n$ causes the probability of switching to increase. Therefore, if $\alpha=0$ or $\sigma^{2}=\infty$, a regime with early specialization will have a lower probability of switching than a regime with late specialization.

\footnotetext{
${ }^{41}$ So $Y^{[k]}$ is a random variable representing observations from an extreme value distribution. See Gupta and Miescke (1994, 1996) and Miescke (1999) for similar decompositions.

${ }^{42}$ This holds so long as switching continues to take place. If $\beta$ is extremely large relative $\alpha$ (e.g. if $\alpha=0$ ) no switching will take place because the loss of skills becomes to large.

${ }^{43}$ This is clear if $\beta=0$ and there is no loss in skills from switching. In this case, a larger $n$ will make $\left(\frac{q}{\pi(\pi+q)}\right)^{1 / 2} Y_{[k]}$ less negative and $-\frac{p}{p+\nu}\left(x_{[k]}-x_{[k-1]}\right)$ more negative, reducing the probability of a switch.
} 
Table 1: Summary Statistics for 1980 College Graduates

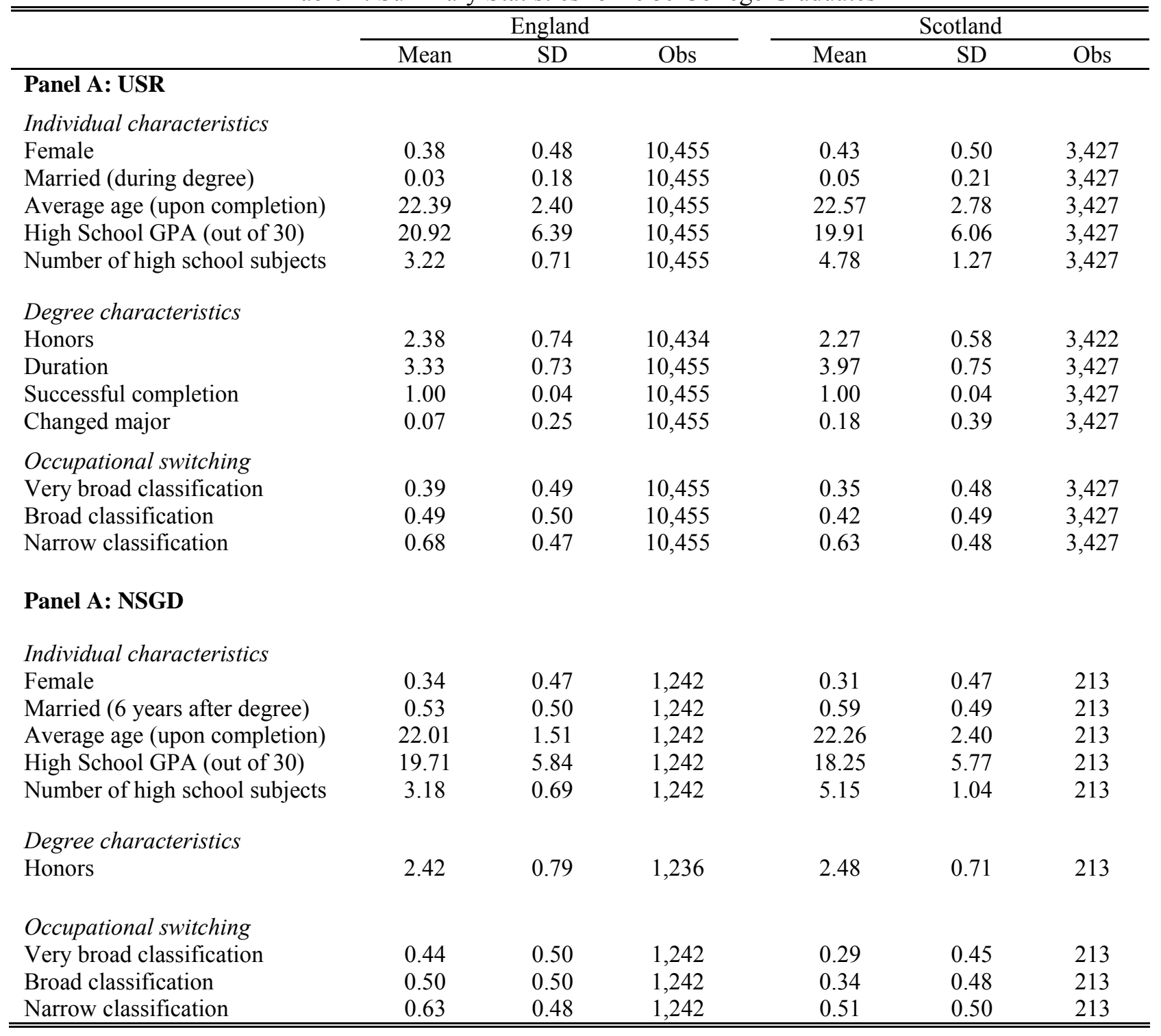

Notes: The base sample for the Universities Statistical Records (USR) includes all individuals who aimed to attain a BA degree in 1980 and were employed in a job during the 1st year following graduation and not pursuing graduate studies. The base sample for the 1980 National Survey of Graduates and Diplomates (NSGD) includes all individuals who attained a BA degree in 1980 and were employed in a job during the 1st year following graduation and not pursuing graduate studies. Median age at the start of the degree is 19 for both nations. GPA is an average measure of the achievement in secondary school leaving exams out of 30 (but standardized by nation in all regressions). Honors is a measure of success at university standardized across nations taking discrete values from 0 (no honors) to 4 (highest honors). Occupational switch is defined as 1 if field of study at the undergraduate level is different from the occupational field of first job 6 months following degree and 0 otherwise (see Data Appendix for further discussion of classification groups). 
Table 2: Further Summary Statistics on Degrees and Destinations for 1980 College Graduates

\begin{tabular}{|c|c|c|c|c|}
\hline & \multicolumn{2}{|c|}{ USR } & \multicolumn{2}{|c|}{ NSGD } \\
\hline & England & Scotland & England & Scotland \\
\hline \multicolumn{5}{|l|}{ Degree Field Composition (\%) } \\
\hline Math and Computer Sciences & 6.44 & 4.20 & 7.57 & 3.76 \\
\hline Physical Sciences & 9.52 & 9.22 & 14.65 & 7.51 \\
\hline Architecture & 1.56 & 1.31 & 1.77 & 2.35 \\
\hline Engineering & 11.41 & 8.70 & 21.18 & 30.05 \\
\hline Life Sciences & 5.96 & 7.56 & 6.76 & 7.98 \\
\hline Health Sciences & 16.15 & 19.67 & 4.27 & 5.16 \\
\hline Social Services and Welfare & 2.94 & 3.68 & 2.98 & 1.88 \\
\hline Social Sciences & 16.06 & 16.72 & 18.92 & 15.49 \\
\hline Business/Accounting & 3.59 & 5.52 & 4.43 & 6.10 \\
\hline Law & 8.13 & 6.45 & 1.29 & 9.86 \\
\hline Education & 1.23 & 1.28 & 3.14 & 4.23 \\
\hline Art & 17.03 & 15.70 & 13.04 & 5.63 \\
\hline \multicolumn{5}{|c|}{ Occupational Field Composition (\%) } \\
\hline Math and Computer Scientists & 5.23 & 4.64 & 11.19 & 6.10 \\
\hline Physical Scientists & 6.74 & 6.36 & 6.04 & 4.23 \\
\hline Architects/Planners & 1.43 & 1.69 & 2.74 & 3.29 \\
\hline Engineers & 10.13 & 7.76 & 21.42 & 30.52 \\
\hline Life Scientists & 0.39 & 0.50 & 2.17 & 3.76 \\
\hline Medical Professionals & 16.56 & 20.51 & 5.56 & 4.69 \\
\hline Social Services Professionals & 1.71 & 2.63 & 3.22 & 2.35 \\
\hline Social Scientists & 2.09 & 2.92 & 1.85 & 2.82 \\
\hline Accountants/Managers & 27.69 & 29.00 & 34.78 & 24.88 \\
\hline Lawyers/Judges & 7.55 & 6.07 & 0.24 & 7.51 \\
\hline Educators/Teachers & 17.24 & 15.76 & 7.89 & 7.98 \\
\hline Artists/Journalists/Entertainers & 3.24 & 2.16 & 2.90 & 1.88 \\
\hline \multicolumn{5}{|l|}{ Post-BA Activity $(\%)^{\mathrm{a}}$} \\
\hline Entering employment & 76.74 & 79.28 & 61.86 & 64.13 \\
\hline Further Study & 11.64 & 10.11 & 27.65 & 29.00 \\
\hline Unemployed & 11.63 & 10.61 & 10.48 & 6.88 \\
\hline \multicolumn{5}{|l|}{ Region of Work (\%) } \\
\hline England & 87.17 & 32.59 & 87.36 & 25.35 \\
\hline Scotland & 1.15 & 61.04 & 1.77 & 70.89 \\
\hline Wales & 1.90 & 1.02 & 3.38 & 0.47 \\
\hline Northern Ireland & 0.37 & 0.50 & 0.32 & 0.00 \\
\hline Abroad & 9.40 & 4.84 & 7.17 & 3.29 \\
\hline \multicolumn{5}{|l|}{ Region of Prior Residence (\%) } \\
\hline England & 91.91 & 15.61 & & \\
\hline Scotland & 0.61 & 81.27 & & \\
\hline Wales & 4.75 & 0.35 & & \\
\hline Northern Ireland & 1.19 & 1.69 & & \\
\hline Abroad & 1.54 & 1.08 & & \\
\hline
\end{tabular}

Notes: Composition of fields of study and occupational fields are based on a broad classification (other classifications are discussed in the Data Appendix). Occupational field represents the field of employment in the 1st year after completing degree. Foreign students returning overseas are excluded from counts of Post-BA activity. ${ }^{a}$ is out of the unrestricted sample including unemployed and graduate students. 
Table 3: Effect of Scottish Degree on Occupational Switching for 1980 College Graduates (USR sample) dependent variable: switched to occupation unrelated to field of study

\section{Panel A: Scotland vs. England}

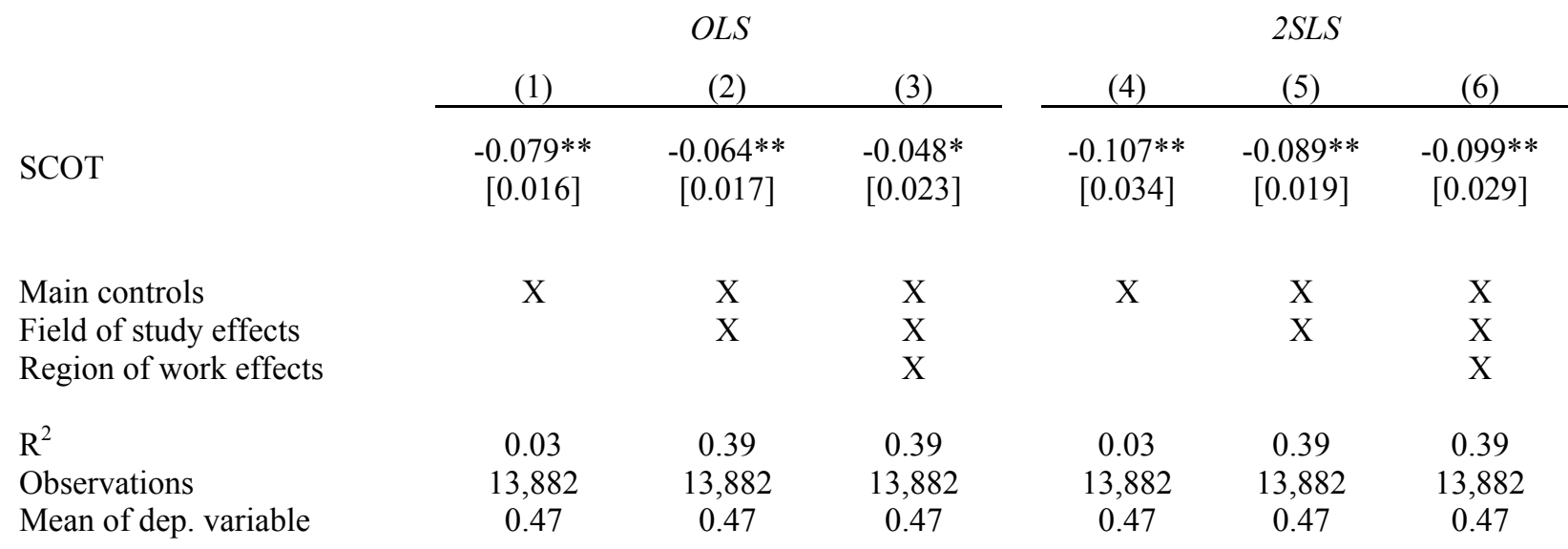

Panel B: Scotland vs. Northern England

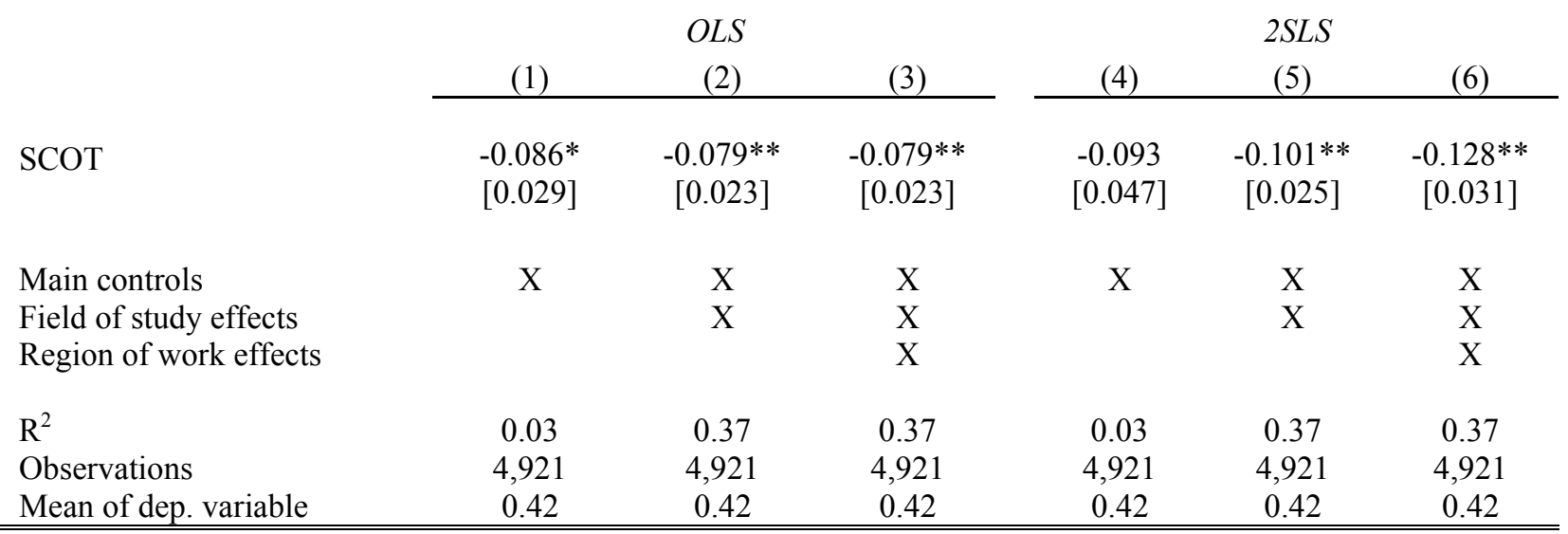

Notes: Huber-White standard errors, clustered by university in brackets. ${ }^{*}$ and $* *$ indicate significance at the $5 \%$ and $1 \%$ level respectively. Sample includes all students who aimed to attain a first degree in England and Scotland with occupation data and were not pursing further studies. Dependent variable is defined as 1 if broad field of study at the undergraduate level is different from the broad occupational field of the first job in the 1st year following degree and 0 otherwise. SCOT is defined as 1 for Scottish degree and 0 for English degree. SCOT is instrumented with nation of prior residence in columns (4), (5), and (6). Main controls include sex, marital status, age, high school GPA, and parent SES. Panel B is restricted to students in England whose region of prior residence was northern England (including North East and Tyne, and all of Yorkshire) 
Table 4: Effect of a Scottish Degree on Occupational Switching for Engineers (USR, 1980-1992)

Dependent variable: switched to occupation unrelated to engineering subfield

\begin{tabular}{|c|c|c|c|c|c|c|}
\hline & & $O L S$ & & & $2 S L S$ & \\
\hline & (1) & (2) & (3) & (4) & (5) & (6) \\
\hline SCOT & $\begin{array}{c}-0.062 \\
{[0.032]}\end{array}$ & $\begin{array}{l}-0.037^{*} \\
{[0.014]}\end{array}$ & $\begin{array}{l}-0.034^{*} \\
{[0.016]}\end{array}$ & $\begin{array}{l}-0.064^{*} \\
{[0.032]}\end{array}$ & $\begin{array}{c}-0.047 * * \\
{[0.012]}\end{array}$ & $\begin{array}{c}-0.049 * * \\
{[0.015]}\end{array}$ \\
\hline Main controls & $\mathrm{X}$ & $\mathrm{X}$ & $\mathrm{X}$ & $\mathrm{X}$ & $\mathrm{X}$ & $\mathrm{X}$ \\
\hline Sub-field effects & & $\mathrm{X}$ & $\mathrm{X}$ & & $\mathrm{X}$ & $\mathrm{X}$ \\
\hline Region of work effects & & & $\mathrm{X}$ & & & $\mathrm{X}$ \\
\hline $\mathrm{R}^{2}$ & 0.02 & 0.29 & 0.29 & 0.02 & 0.29 & 0.29 \\
\hline Observations & 21,819 & 22,320 & 22,320 & 22,320 & 22,320 & 22,320 \\
\hline Mean of dep. variable & 0.28 & 0.28 & 0.28 & 0.28 & 0.28 & 0.28 \\
\hline
\end{tabular}

Notes: Huber-White standard errors, clustered by university in brackets (that the standard errors are larger for OLS than 2SLS may occur because of the strong first stage and the cross-correlations within the clustered groups). * and ** indicate significance at the $5 \%$ and $1 \%$ level respectively. Sample includes all students who aimed to attain a first engineering degree in England and Scotland with occupation data and were not pursing further studies. Dependent variable is defined as 1 if the engineering subfield at the undergraduate level is different from the engineering subfield of the first job in the 1st year following degree and 0 otherwise. SCOT is defined as 1 for Scottish degree and 0 for English degree. SCOT is instrumented with nation of prior residence in columns (4), (5), and (6). Main controls include sex, marital status, age, high school GPA, parent SES and year fixed effects. 
Table 5: Effect of Scottish Degree on Occupational Switching for 1980 College Graduates (NSGD) dependent variable: switched to occupation unrelated to field of study

\begin{tabular}{|c|c|c|c|c|c|c|}
\hline & \multicolumn{3}{|c|}{$\mathbf{1}^{\text {st }}$ year after completing degree } & \multicolumn{3}{|c|}{$\mathbf{6}^{\text {th }}$ year after completing degree } \\
\hline & $(1)$ & $(2)$ & $(3)$ & $(4)$ & $(5)$ & $(6)$ \\
\hline SCOT & $\begin{array}{c}-0.151 * * \\
{[0.035]}\end{array}$ & $\begin{array}{c}-0.086^{* *} \\
{[0.028]}\end{array}$ & $\begin{array}{c}0.014 \\
{[0.045]}\end{array}$ & $\begin{array}{c}-0.174 * * \\
{[0.036]}\end{array}$ & $\begin{array}{c}-0.110 * * \\
{[0.029]}\end{array}$ & $\begin{array}{c}-0.053 \\
{[0.046]}\end{array}$ \\
\hline Main controls & $\mathrm{X}$ & $\mathrm{X}$ & $\mathrm{X}$ & $\mathrm{X}$ & $\mathrm{X}$ & $\mathrm{X}$ \\
\hline Field of study effects & & $\mathrm{X}$ & $\mathrm{X}$ & & $\mathrm{X}$ & $\mathrm{X}$ \\
\hline Region of work effects & & & $\mathrm{X}$ & & & $\mathrm{X}$ \\
\hline $\mathrm{R}^{2}$ & 0.03 & 0.35 & 0.36 & 0.03 & 0.30 & 0.31 \\
\hline Observations & 1,455 & 1,455 & 1,455 & 1,455 & 1,455 & 1,455 \\
\hline Mean of dep. variable & 0.48 & 0.48 & 0.48 & 0.52 & 0.52 & 0.52 \\
\hline
\end{tabular}

Notes: Huber-White standard errors, clustered by university in brackets. * and ** indicate significance at the 5\% and $1 \%$ level respectively. Sample includes all students who aimed to attain a first degree in England and Scotland with occupation data and were not pursing further studies. Dependent variable is defined as 1 if field of study at the undergraduate level is different from the broad occupational field of the first job in the 1st year following the degree and 0 otherwise. SCOT is defined as 1 for having completed Scottish school leaving exams and 0 for English school leaving exams. Main controls include sex, marital status, age, high school GPA, and parent SES. 
Table 6: "Placebo Tests" of Occupational Switching

dependent variable: switched to occupation unrelated to field of study

Panel A: Wales vs. England (USR sample)

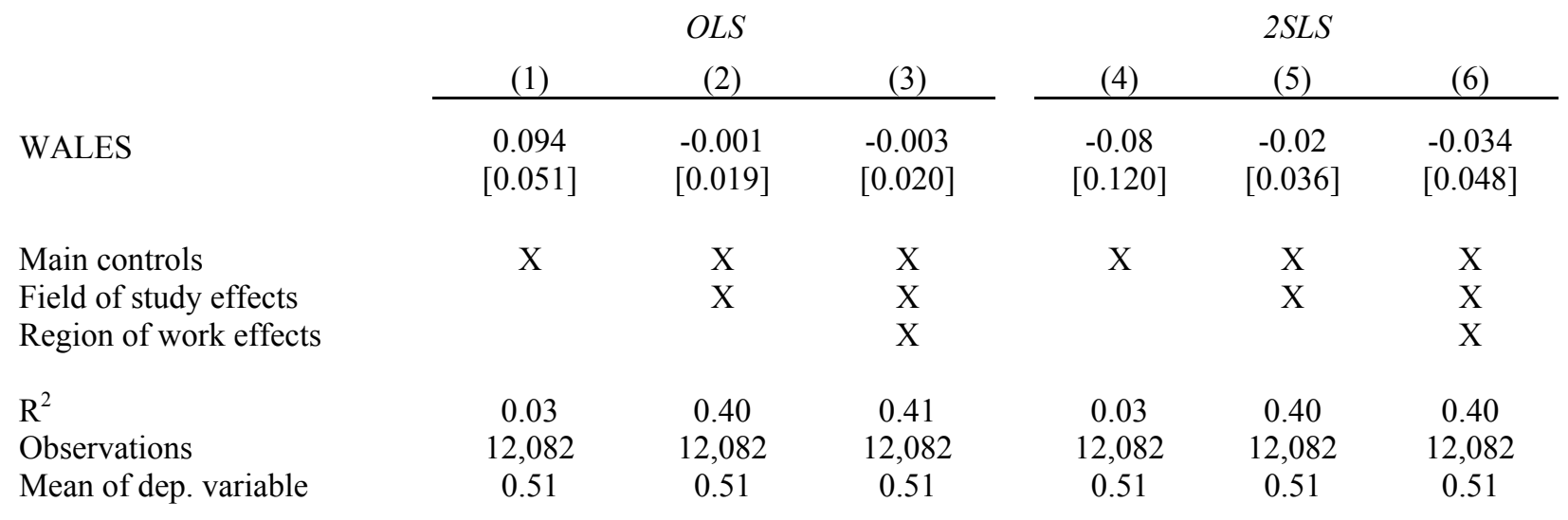

Panel B: Graduate-level Occupational Switching in Scotland and England

USR Sample (OLS) NSGD sample (reduced form)

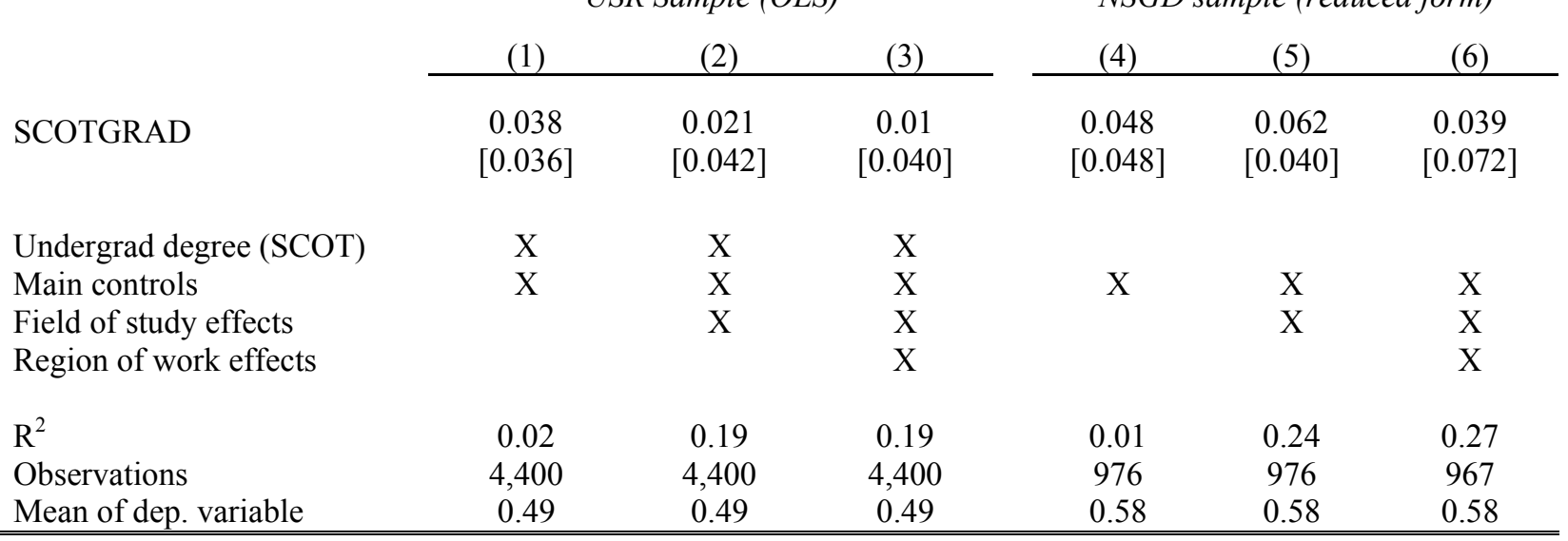

Notes: Huber-White standard errors, clustered by university in brackets. * and ** indicate significance at the $5 \%$ and $1 \%$ level respectively. Dependent variable in Panel A is defined as 1 if the broad field of study at the undergraduate level is different from the broad occupational field of first job in the 1st year following degree and 0 otherwise. WALES is defined as 1 for Welsh degree and 0 for English degree. WALES is instrumented with nation of prior residence in columns (4), (5), and (6) of Panel A. Main controls include sex, marital status, age, high school GPA, and parent SES. Dependent variable in Panel B is defined as 1 if the broad field of study at the graduate level is different from the broad occupational field of first job in the 1st year following degree and 0 otherwise. SCOTGRAD is defined as 1 for graduate Scottish degree and 0 for graduate English degree. Columns (4), (5), and (6) of Panel B show the reduced form using Scottish school leaving exams as a proxy for a Scottish graduate degree. Main controls for the USR in Panel B include sex, marital status and age. Main controls for the NSGD include sex, marital status, age, high school GPA, and parent SES. 
Appendix Table 1: Classification of Fields and Occupations

\begin{tabular}{|c|c|c|c|}
\hline Fields & S Subject codes (NSGD/USR-1980) & "Occupational Codes (NSGD) & "Occupational Codes (USR-1980) \\
\hline $\begin{array}{l}\text { 111 Math/Comp. Science } \\
1111 \text { Math Sciences } \\
1112 \text { Computer Sciences } \\
112 \text { Physical Sciences }\end{array}$ & $\begin{array}{l}\text { Mathematics (81) } \\
\text { Computer Science (82); Math/Comp. Science (31) }\end{array}$ & $\begin{array}{l}\text { Mathematician (444); Statistician }(242) \ldots \\
\text { Computer Programmer (244); Analyst/programmer (246)... }\end{array}$ & $\begin{array}{l}\text { Operational research (441); Statistician (452) } \\
\text { Systems analysis (442); Computer programming (443)... }\end{array}$ \\
\hline $\begin{array}{l}1121 \text { Chemistry } \\
1122 \text { Geology } \\
1123 \text { Physics }\end{array}$ & $\begin{array}{l}\text { Chemistry (34); Environmental Science (36) } \\
\text { Geology (35) } \\
\text { Physics (33); Mathematics/Physics (32) }\end{array}$ & $\begin{array}{l}\text { Chemical scientist (442) } \\
\text { Geological scientist (445) } \\
\text { Physical scientist (443) }\end{array}$ & $\begin{array}{l}\text { Scientist (510) + Chemical and allied industries (240-247) } \\
\text { Scientist (510) + Oil, mining industries (230-235) } \\
\text { Scientist (510) + Atomic energy (284); Other manufacturing }\end{array}$ \\
\hline $\begin{array}{l}121 \text { Architecture } \\
1210 \text { Architecture } \\
\text { 122 Engineering }\end{array}$ & Architecture (51); Town plan (52); Surveying (17) & Architect (511); Town planning (514); Draughtsman & Architect (551); Town planning (553); Surveying \\
\hline $\begin{array}{l}1221 \text { Mechanical } \\
1222 \text { Chemical } \\
1223 \text { Civil } \\
1224 \text { Electrical } \\
1225 \text { Industrial } \\
1226 \text { Materials } \\
1227 \text { Aeronautical }\end{array}$ & $\begin{array}{l}\text { Mechanical engineering (12) } \\
\text { Chemical Engineering (9) } \\
\text { Civil Engineering (10) } \\
\text { Electrical Engineering (11) } \\
\text { Production engineering (13) } \\
\text { Mining (14); Metallurgy (15) } \\
\text { Aeronautical engineer. (8) }\end{array}$ & $\begin{array}{l}\text { Mechanical or aeronautical engineer (461) } \\
\text { Chemical engineer ( } 481) \\
\text { Civil, municipal or structural engineer }(451) \ldots \\
\text { Electrical engineer (471); Electronic engineer }(472,473) \\
\text { Production engineer (482); Planning engineer }(483) \ldots \\
\text { Mining engineer (452); Metallurgist }(485) \\
\text { Mechanical or aeronautical engineer }(461)\end{array}$ & 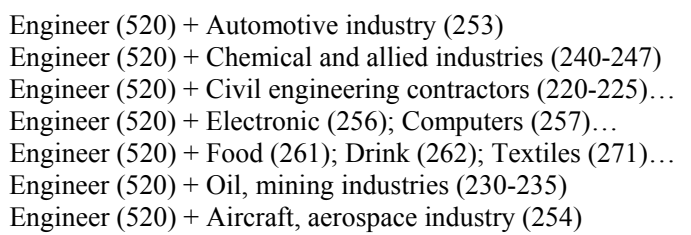 \\
\hline $\begin{array}{l}131 \text { Life Sciences } \\
1311 \text { Agriculture } \\
1312 \text { Biology }\end{array}$ & 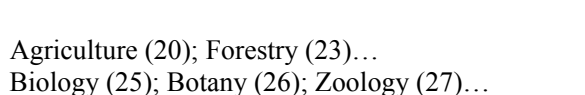 & $\begin{array}{l}\text { Farmer, farm manager, horticulturist ( } 600) \\
\text { Biological scientist, biochemist (441) }\end{array}$ & $\begin{array}{l}\text { Scientist (510) + Agriculture, horticulture, forestry }(210-214) \\
\text { Scientist }(510)+\text { Health authorities }(154)\end{array}$ \\
\hline $\begin{array}{l}132 \text { Health Sciences } \\
1321 \text { Physicians } \\
1322 \text { Dentists/Vets/Pharm } \\
1323 \text { Nursing/Related }\end{array}$ & $\begin{array}{l}\text { Medicine (3) } \\
\text { Dentistry (4); Veterinary (24); Pharmacology }(5,6) \\
\text { Studies allied to medicine/health (7) }\end{array}$ & $\begin{array}{l}\text { Medical practitioner (351) } \\
\text { Dentist (352); Veterinarian (382); Pharmacist (371)... } \\
\text { Nurse (360); Physiotherapist (374)... }\end{array}$ & $\begin{array}{l}\text { Medicine (631); Medical \& para-medical services (630) } \\
\text { Dentistry (632); Veterinary (640); Pharmacy (634)... } \\
\text { Nursing (633); Physio-occupational, speech \& therapy (636) }\end{array}$ \\
\hline $\begin{array}{l}2111 \text { Psychology } \\
2112 \text { Sociology/Social Work } \\
\text { 212 Social Sciences }\end{array}$ & $\begin{array}{l}\text { Psychology (46) } \\
\text { Sociology (47) }\end{array}$ & $\begin{array}{l}\text { Psychologist (324) } \\
\text { Sociologist (323); Welfare worker (333)... }\end{array}$ & $\begin{array}{l}\text { Psychology (623); Occupational guidance }(624) \\
\text { Social, welfare, religious (620); Social/welfare }(621) \ldots\end{array}$ \\
\hline $\begin{array}{l}2121 \text { Economics } \\
2122 \text { History/ Geography } \\
2123 \text { Govt., Public Admin. } \\
2124 \text { Other Social } \\
221 \text { Business }\end{array}$ & $\begin{array}{l}\text { Economics (41) } \\
\text { History (69); Archeology (70); Geography (42) } \\
\text { Government and public administration (44) } \\
\text { Social anthropology (48) }\end{array}$ & $\begin{array}{l}\text { Economist (241) } \\
\text { Librarian, information officer (294) } \\
\text { Inspector (263); General administration (local govt) (280)... } \\
\text { Social or behavioural scientist (325) }\end{array}$ & $\begin{array}{l}\text { Economic (450); Economist (451) } \\
\text { Librarian (721) Archivist (722) } \\
\text { Consumer protection, environmental health, safety }(653) \ldots \\
\text { Non-scientific research (730); Information research }(700) \ldots\end{array}$ \\
\hline $\begin{array}{l}2211 \text { Accounting, Finance } \\
2212 \text { Management } \\
2213 \text { Sales } \\
2214 \text { Related Business }\end{array}$ & $\begin{array}{l}\text { Accountancy }(43) \\
\text { Business, management studies }(40,53) \\
\text { Business, management studies }(40,53) \\
\text { Secretarial studies }(84)\end{array}$ & 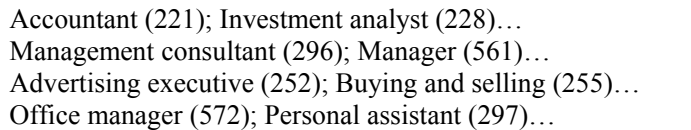 & $\begin{array}{l}\text { Financial (460); Accountancy (461); Banking }(462) \ldots \\
\text { Management \& supporting occupations }(400) \ldots \\
\text { Purchasing ( } 431) \text {; Selling (432); Marketing (434)... } \\
\text { Clerical, secreterial \& related (930)... }\end{array}$ \\
\hline $\begin{array}{l}222 \text { Law } \\
2220 \text { Law } \\
231 \text { Education }\end{array}$ & Law (45) & Judge (211); Advocate, barrister (212); Solicitor (213). & Baristor (471); Solicitor (472); Trusts (473).. \\
\hline $\begin{array}{l}2310 \text { Education } \\
232 \text { Arts }\end{array}$ & Education (1) & Teacher (secondary) (311); Teacher (primary) (312)... & Primary (611); Middle school (612); Secondary (613)... \\
\hline $\begin{array}{l}2321 \text { English/Languages } \\
2322 \text { Art } \\
2323 \text { Performing arts } \\
2324 \text { Religion/Philosophy }\end{array}$ & $\begin{array}{l}\text { English (55); French (57); German (59)... } \\
\text { Art (73) } \\
\text { Drama (74); Music (75) } \\
\text { Religion (72); Philosophy (71) }\end{array}$ & $\begin{array}{l}\text { Author, writer, journalist, editor (391) } \\
\text { Artist, commercial artist (401); Designer (402-406) } \\
\text { Actor, entertainer, musician, singer, stage manager (411)... } \\
\text { Clergy, minister of religion (340) }\end{array}$ & $\begin{array}{l}\text { Journalist (811); Technical writer ( } 711) \text {; Translater (712)... } \\
\text { Art, sculpture, design ( } 820) \text {; Fashion \& textiles ( } 823) \ldots \\
\text { Acting, music, sport (830); Broadcasting/stage/film (840)... } \\
\text { Pastoral (622) }\end{array}$ \\
\hline
\end{tabular}

Notes: Subject codes for USR are correct for 1972-1984 (different codes for 1985-1993) and occupational codes for the USR are correct from 1980-1993 (different codes for 19731979). Occupational codes omit some categories for brevity and indicated with “..." when excluded. Engineers and scientist in the USR are matched with industry codes in order to identify particular specializations within each category. Further details are available from the author. Broad fields are in bold. Very broad fields are expressed by the 2-digit codes. 


\begin{tabular}{|c|c|c|}
\hline & $\begin{array}{l}\text { USR } \\
(1)\end{array}$ & $\begin{array}{c}\text { NSGD } \\
(2)\end{array}$ \\
\hline Baseline & $\begin{array}{c}-0.089 * * \\
{[0.019]}\end{array}$ & $\begin{array}{c}-0.086^{* *} \\
{[0.028]}\end{array}$ \\
\hline \multicolumn{3}{|l|}{ Classification of Fields } \\
\hline Narrow & $\begin{array}{c}-0.077^{*} \\
{[0.029]}\end{array}$ & $\begin{array}{c}-0.062 \\
{[0.034]}\end{array}$ \\
\hline Very Broad & $\begin{array}{c}-0.059^{* *} \\
{[0.010]}\end{array}$ & $\begin{array}{l}-0.070^{*} \\
{[0.028]}\end{array}$ \\
\hline \multicolumn{3}{|l|}{ Occupational Restrictions } \\
\hline Unemployed as Switch & $\begin{array}{c}-0.050^{* *} \\
{[0.010]}\end{array}$ & $\begin{array}{c}-0.089 * * \\
{[0.028]}\end{array}$ \\
\hline Unclassified Occupations as Switch & $\begin{array}{c}-0.054^{* *} \\
{[0.014]}\end{array}$ & $\begin{array}{c}-0.064 * \\
{[0.026]}\end{array}$ \\
\hline Include Graduate Students & $\begin{array}{c}-0.050^{* *} \\
{[0.011]}\end{array}$ & $\begin{array}{c}-0.088^{* *} \\
{[0.028]}\end{array}$ \\
\hline Graduate Students as Non-switch & $\begin{array}{c}-0.052 * * \\
{[0.010]}\end{array}$ & $\begin{array}{c}-0.086^{* *} \\
{[0.028]}\end{array}$ \\
\hline \multicolumn{3}{|l|}{ Field Restrictions } \\
\hline Exclude Education & $\begin{array}{c}-0.052 * * \\
{[0.011]}\end{array}$ & $\begin{array}{c}-0.092 * * \\
{[0.029]}\end{array}$ \\
\hline Education as Non-switch & $\begin{array}{c}-0.052 * * \\
{[0.011]}\end{array}$ & $\begin{array}{c}-0.089 * * \\
{[0.028]}\end{array}$ \\
\hline Exclude Business & $\begin{array}{c}-0.051 * * \\
{[0.011]}\end{array}$ & $\begin{array}{c}-0.079^{* *} \\
{[0.030]}\end{array}$ \\
\hline Business as Non-Switch & $\begin{array}{c}-0.048^{* *} \\
{[0.010]}\end{array}$ & $\begin{array}{c}-0.074 * * \\
{[0.028]}\end{array}$ \\
\hline Exclude Combined fields & $\begin{array}{c}-0.052^{* *} \\
{[0.010]}\end{array}$ & $\begin{array}{c}-0.107 * * \\
{[0.028]}\end{array}$ \\
\hline \multicolumn{3}{|l|}{ Population restrictions } \\
\hline Restrict to highest GPA students & $\begin{array}{l}-0.038^{*} \\
{[0.016]}\end{array}$ & $\begin{array}{c}-0.081 \\
{[0.065]}\end{array}$ \\
\hline
\end{tabular}

Notes: Huber-White standard errors in brackets, clustered by university for USR samples. *, **, indicate significance at the $5 \%$ and $1 \%$ level respectively. Coefficients from the USR sample are for 2SLS with main controls, controls for field of study, but no controls for region of work. Coefficients on occupational switching from in the NSGD sample include main controls, controls for field of study, but no controls for region of work. Coefficients on all wage regressions include main controls, controls for field of study, region of work, and industry. 
Appendix Table 3: Occupational Switching by Field (USR, 1980-92)

\begin{tabular}{|c|c|c|c|c|c|c|c|c|c|c|c|c|}
\hline & Math/Comp & Physical & Architect & Engineer & Biology & Health & Social Serv. & Social Sci. & Business & Law & $E d u c$ & Arts \\
\hline SCOT & $\begin{array}{c}-0.143 * \\
{[0.054]}\end{array}$ & $\begin{array}{c}-0.051 * \\
{[0.022]}\end{array}$ & $\begin{array}{c}-0.141 \\
{[0.070]}\end{array}$ & $\begin{array}{c}-0.097 * * \\
{[0.020]}\end{array}$ & $\begin{array}{c}-0.102 * * \\
{[0.027]}\end{array}$ & $\begin{array}{c}-0.003 \\
{[0.012]}\end{array}$ & $\begin{array}{c}-0.076^{* *} \\
{[0.020]}\end{array}$ & $\begin{array}{c}-0.102 * * \\
{[0.028]}\end{array}$ & $\begin{array}{c}-0.031 \\
{[0.022]}\end{array}$ & $\begin{array}{c}-0.042 * \\
{[0.018]}\end{array}$ & $\begin{array}{c}-0.038 \\
{[0.054]}\end{array}$ & $\begin{array}{c}-0.205 * * \\
{[0.066]}\end{array}$ \\
\hline Main controls & $\mathrm{X}$ & $\mathrm{X}$ & $\mathrm{X}$ & $\mathrm{X}$ & $\mathrm{X}$ & $\mathrm{X}$ & $\mathrm{X}$ & $\mathrm{X}$ & $\mathrm{X}$ & $\mathrm{X}$ & $\mathrm{X}$ & $\mathrm{X}$ \\
\hline Observations & 12,861 & 16,535 & 2,516 & 21,819 & 11,112 & 33,354 & 5,739 & 25,111 & 8,745 & 14,410 & 2,804 & 26,114 \\
\hline $\mathrm{R}^{2}$ & 0.04 & 0.08 & 0.07 & 0.02 & 0.01 & 0.03 & 0.02 & 0.02 & 0.01 & 0.01 & 0.09 & 0.04 \\
\hline $\begin{array}{l}\text { Mean of dep. } \\
\text { variable }\end{array}$ & 0.64 & 0.76 & 0.19 & 0.28 & 0.73 & 0.04 & 0.76 & 0.86 & 0.08 & 0.14 & 0.16 & 0.78 \\
\hline
\end{tabular}

Notes: Huber-White standard errors, clustered by university in brackets. * and ** indicate significance at the $5 \%$, and $1 \%$ level respectively. Sample includes all students who aimed to attain a first degree in England and Scotland with occupation data and were not pursing further studies. Dependent variable is defined as 1 if broad field of study at the undergraduate level is different from the broad occupational field in the 1st year following degree and 0 otherwise. SCOT is defined as 1 for Scottish degree and 0 for English degree. Main controls include sex, marital status, age, high school GPA, parent SES, and year fixed effects. 
Appendix Table 4: Percentage Employment in Different Occupational Fields by Field of Study in 1980 BA Degree (USR)

\section{ENGLAND}

Occupational Field

\begin{tabular}{|c|c|c|c|c|c|c|c|c|c|c|c|c|c|}
\hline Field of Study & unclassified & Math/Comp & Physical & Architect & Engineer & Bio & Health & Social Serv. & Social Sci. & Business & Law & $E d u c$ & Arts \\
\hline Math/Comp & 2.7 & 38.3 & 7.2 & 0.1 & 5.7 & 0.0 & 0.1 & 0.8 & 0.4 & 27.9 & 0.1 & 15.8 & 0.8 \\
\hline Physical Sci. & 6.8 & 11.2 & 31.3 & 0.8 & 9.8 & 0.3 & 0.9 & 1.1 & 2.5 & 18.6 & 0.6 & 14.6 & 1.3 \\
\hline Architecture & 10.0 & 0.2 & 1.5 & 57.1 & 0.0 & 0.2 & 0.0 & 0.2 & 0.4 & 28.6 & 0.2 & 0.9 & 0.7 \\
\hline Engineering & 5.8 & 2.6 & 7.1 & 1.1 & 71.3 & 0.1 & 0.2 & 0.5 & 0.3 & 8.9 & 0.1 & 1.5 & 0.6 \\
\hline Biology & 12.0 & 3.9 & 25.8 & 0.4 & 0.8 & 3.4 & 5.0 & 1.4 & 2.3 & 25.8 & 0.4 & 17.4 & 1.5 \\
\hline Health & 0.3 & 0.1 & 2.2 & 0.0 & 0.1 & 0.2 & 94.4 & 0.1 & 1.0 & 1.0 & 0.0 & 0.6 & 0.1 \\
\hline Social Serv & 11.0 & 2.9 & 1.3 & 0.2 & 0.2 & 0.4 & 7.6 & 24.2 & 4.1 & 23.6 & 1.0 & 21.4 & 2.0 \\
\hline Social Sci. & 13.2 & 3.0 & 0.6 & 1.6 & 0.2 & 0.0 & 0.9 & 2.5 & 6.0 & 47.5 & 2.5 & 18.8 & 3.4 \\
\hline Business & 3.9 & 3.3 & 0.2 & 0.4 & 0.8 & 0.0 & 0.2 & 0.3 & 0.9 & 87.6 & 0.4 & 1.9 & 0.3 \\
\hline Law & 2.0 & 0.2 & 0.1 & 0.0 & 0.1 & 0.0 & 0.1 & 0.5 & 1.8 & 11.8 & 81.8 & 0.9 & 0.7 \\
\hline Education & 5.9 & 0.8 & 0.2 & 0.0 & 0.3 & 0.0 & 5.6 & 2.2 & 0.0 & 7.0 & 0.3 & 76.9 & 0.8 \\
\hline Arts & 16.6 & 1.6 & 0.1 & 0.1 & 0.1 & 0.0 & 1.5 & 2.2 & 4.0 & 26.5 & 1.5 & 34.7 & 11.3 \\
\hline \multicolumn{14}{|l|}{ SCOTLAND } \\
\hline \multicolumn{14}{|c|}{ Occupational Field } \\
\hline Field of Study & unclassified & Math/Comp & Physical & Architect & Engineer & Bio & Health & Social Serv. & Social Sci. & Business & Law & $E d u c$ & Arts \\
\hline Math/Comp & 1.6 & 49.8 & 6.2 & 0.0 & 2.3 & 0.0 & 0.0 & 0.0 & 0.4 & 24.1 & 0.0 & 15.6 & 0.0 \\
\hline Physical Sci. & 6.5 & 7.4 & 31.7 & 0.3 & 14.8 & 0.9 & 0.3 & 0.0 & 0.6 & 15.1 & 0.0 & 21.5 & 0.9 \\
\hline Architecture & 10.1 & 0.9 & 0.0 & 74.3 & 0.9 & 0.0 & 0.0 & 1.8 & 1.8 & 10.1 & 0.0 & 0.0 & 0.0 \\
\hline Engineering & 4.3 & 2.1 & 5.7 & 0.3 & 74.1 & 0.0 & 0.2 & 0.2 & 0.3 & 9.9 & 0.0 & 2.9 & 0.0 \\
\hline Biology & 14.6 & 1.7 & 24.9 & 0.9 & 0.9 & 3.5 & 4.7 & 1.2 & 3.1 & 25.2 & 0.2 & 17.9 & 1.2 \\
\hline Health & 0.0 & 0.0 & 0.5 & 0.0 & 0.0 & 0.1 & 97.4 & 0.0 & 0.9 & 0.8 & 0.0 & 0.2 & 0.1 \\
\hline Social Serv. & 13.1 & 5.0 & 2.3 & 0.5 & 0.0 & 0.0 & 4.5 & 26.7 & 2.7 & 28.5 & 0.9 & 14.5 & 1.4 \\
\hline Social Sci. & 9.6 & 2.7 & 0.7 & 3.7 & 0.2 & 0.2 & 0.7 & 4.5 & 8.4 & 44.6 & 1.3 & 19.6 & 3.9 \\
\hline Business & 2.7 & 0.3 & 0.0 & 0.0 & 0.3 & 0.0 & 0.9 & 0.0 & 0.0 & 94.7 & 0.6 & 0.3 & 0.3 \\
\hline Law & 1.1 & 0.0 & 0.0 & 0.0 & 0.2 & 0.0 & 0.2 & 0.4 & 1.3 & 8.7 & 88.1 & 0.0 & 0.0 \\
\hline Education & 6.6 & 0.0 & 0.0 & 0.0 & 0.0 & 0.0 & 19.7 & 0.8 & 0.0 & 4.9 & 0.0 & 68.0 & 0.0 \\
\hline Arts & 12.8 & 0.8 & 0.0 & 0.0 & 0.3 & 0.0 & 0.9 & 2.2 & 4.5 & 24.5 & 0.9 & 38.8 & 14.3 \\
\hline
\end{tabular}


Figure 1: Probability of Occupational Switching by Relative Return to Match Quality

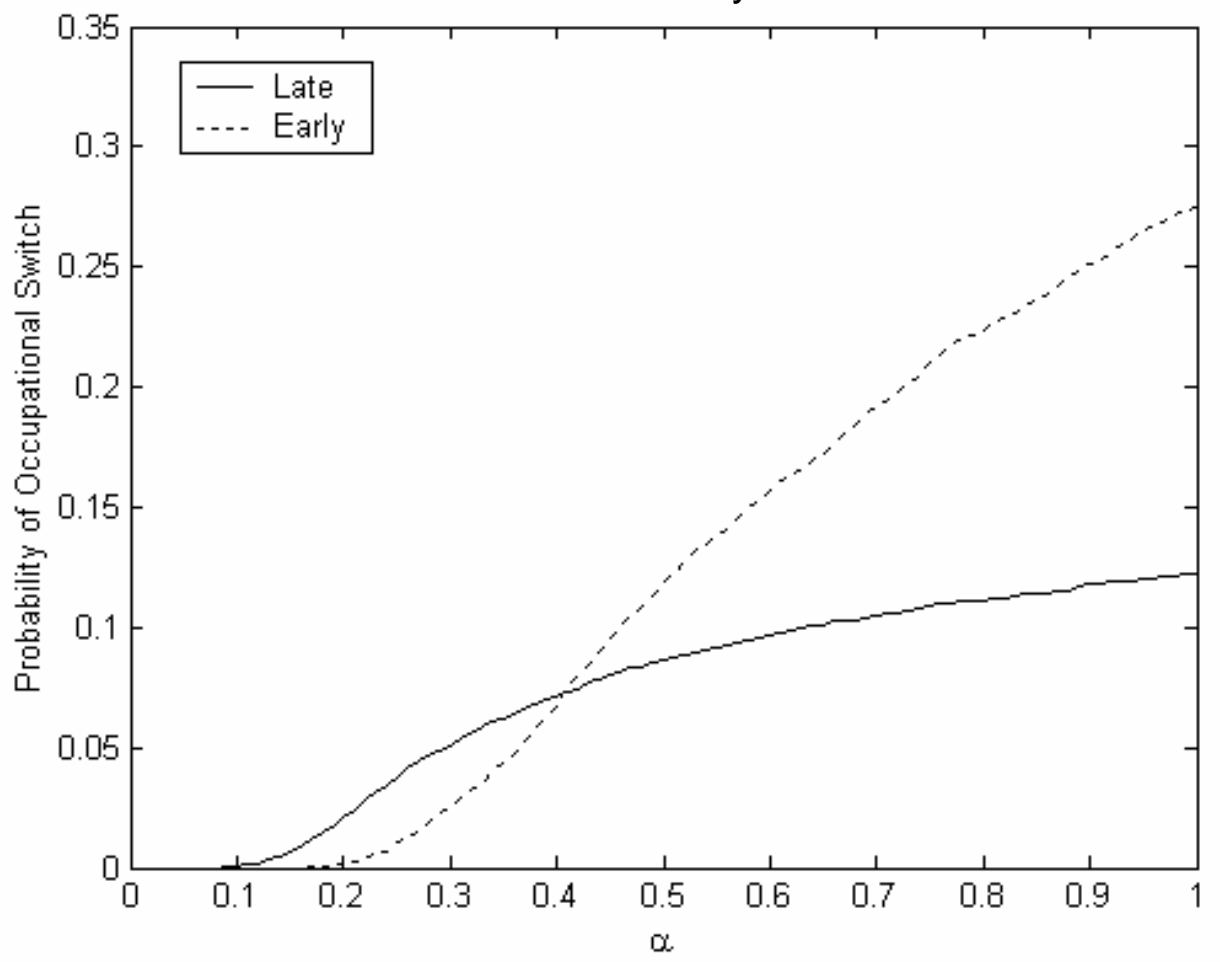

Figure 2: Expected Returns by Relative Return to Match Quality

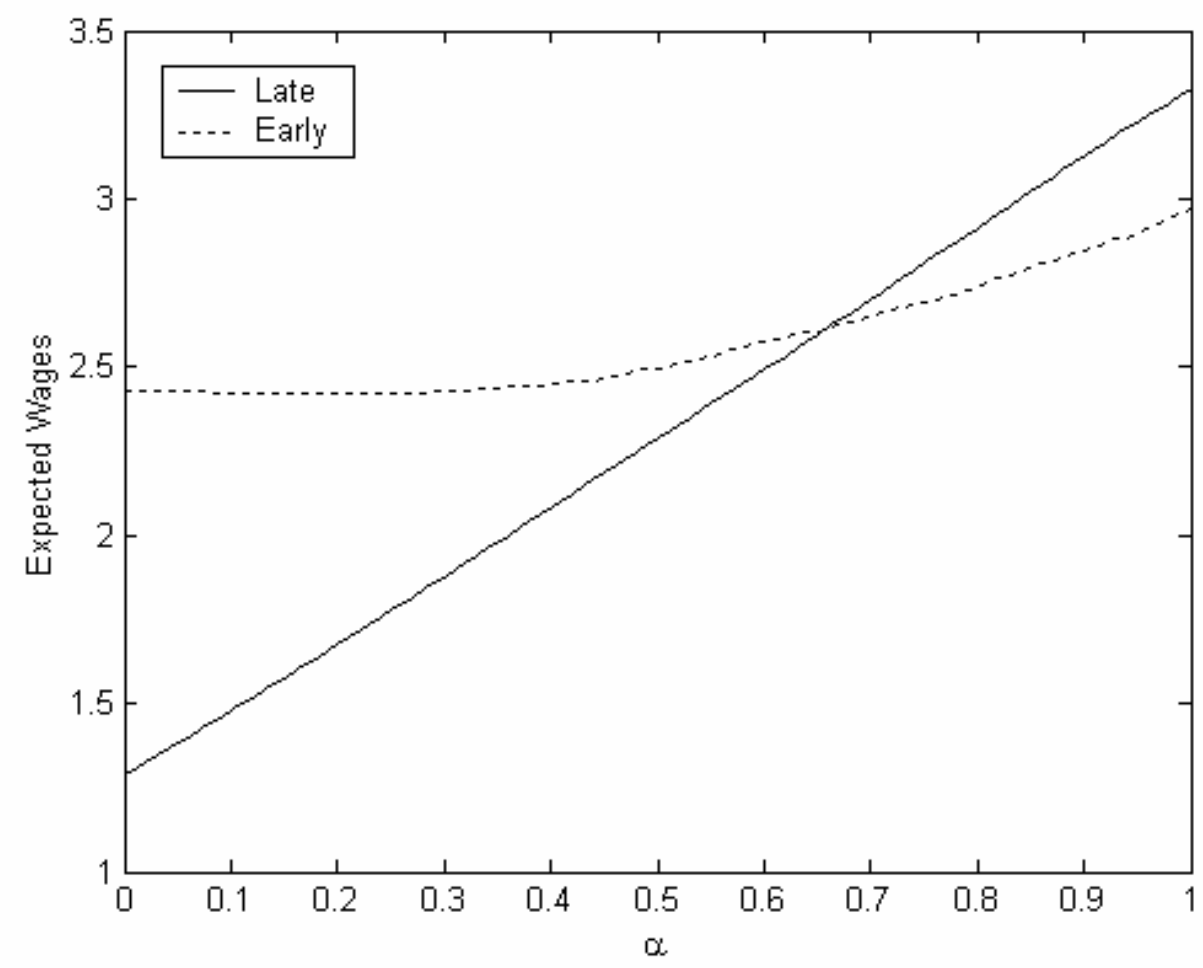

Notes: All simulations are based on 5000 repetitions for $\mathrm{k}=2, N=21, \mu=0, \sigma_{0}=25$, and $\sigma=100$. Early regimes are characterized by $n^{E}=2$; late regimes are characterized by $n^{L}=6$. The relative returns to match quality are normalized by taking $\beta=(1-\alpha)$ so that $(\alpha / \beta)$ goes from 0 to $\infty$ as $\alpha$ goes from 0 to 1 . Expected wages are log wages determined according to $E\left(\ln w_{j}\right)=E\left(\alpha \theta_{i}+\beta s_{i}\right)$ where $s_{i}=\left[s_{i} /(N / k)\right]+\mu$ are normalized skills. 
Figure 3: Outcomes by Year of Graduation (USR sample)
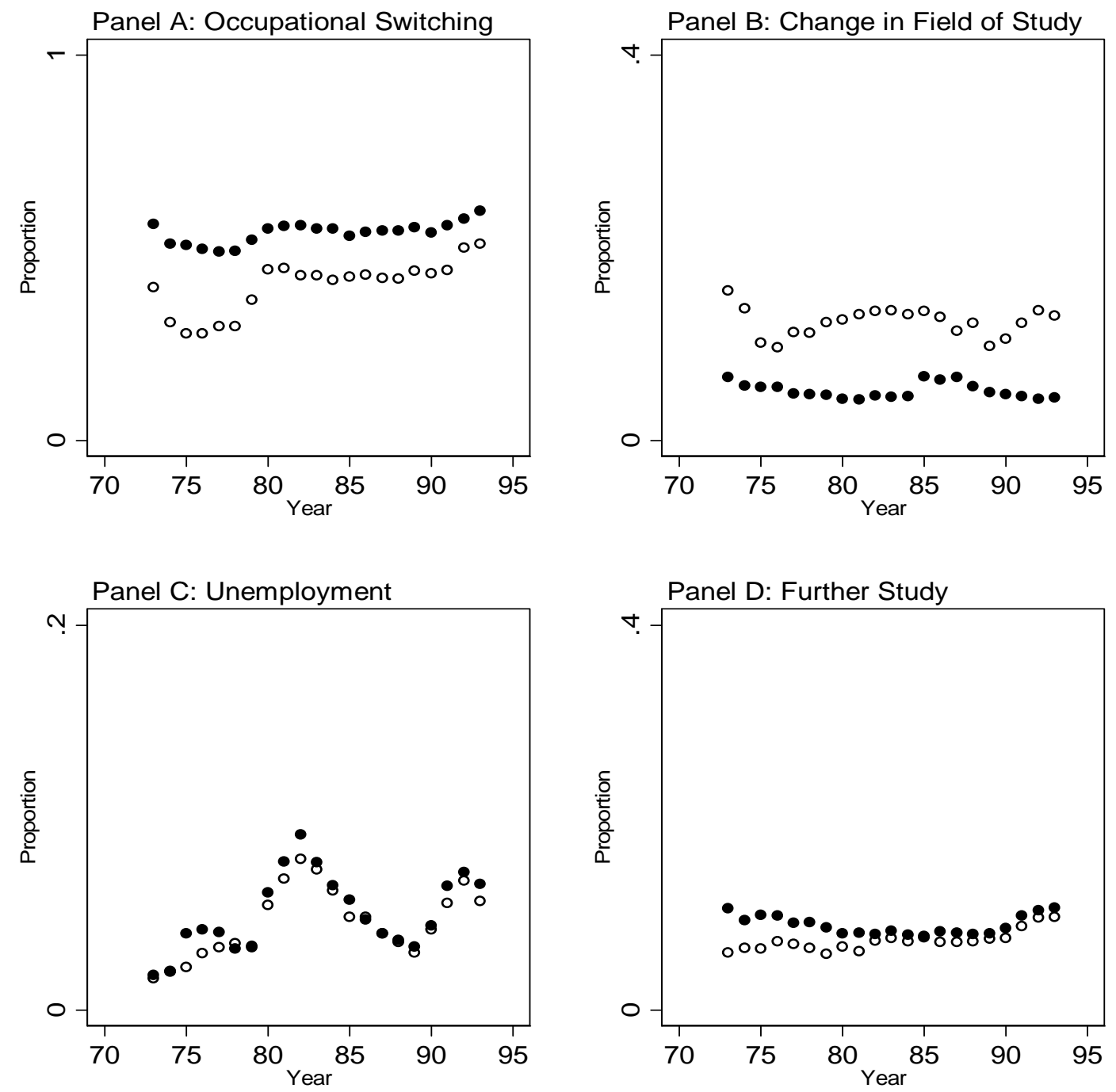

Notes: Closed and open circles represent England and Scotland averages respectively. Outcomes based on USR samples of undergraduates from 1973-1993. Field switching is calculated with the broad classification (see Appendix Table 1). Change of field of study is determined by students who receive a degree in a field different from the one they applied for. Unemployment and Further study are during the $1^{\text {st }}$ year following graduation. 
Figure 4: Changes in Major and Field Switching by University (USR)

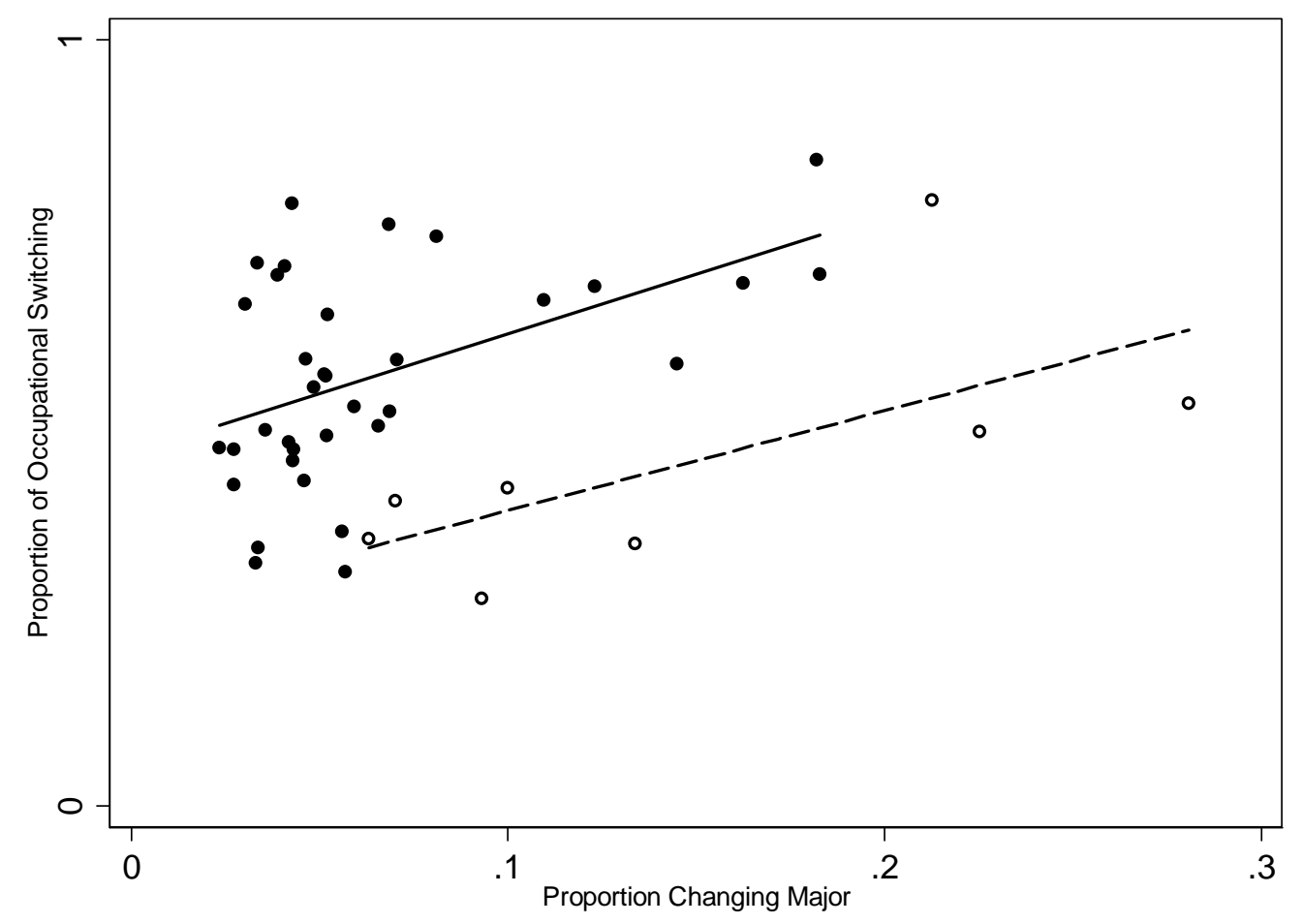

Notes: Closed and open circles represent English and Scottish university averages respectively. Outcomes based on USR samples of undergraduates from 1973-1993. Field switching is calculated with the broad classification (see Appendix Table 1). Change of field of study is determined by students who receive a degree in a field different from the one they applied for. 